OPEN ACCESS

Edited by:

Carlos Chavez Olortegui,

Federal University of Minas Gerais,

Brazil

Reviewed by:

Clara Guerra-Duarte,

Fundação Ezequiel Dias (FUNED),

Brazil

Adolfo Borges,

Center for the Development of Scientific Research (CEDIC),

Paraguay

Jader S. Cruz,

Federal University of Minas Gerais,

Brazi

*Correspondence:

Manuela B. Pucca

manu.pucca@ufrr.br;

manupucca@hotmail.com

tThese authors have contributed equally to this work

Specialty section:

This article was submitted to Vaccines and Molecular Therapeutics, a section of the journal

Frontiers in Immunology

Received: 09 May 2020

Accepted: 24 July 2020

Published: 20 August 2020

Citation:

Abreu CB, Bordon KCF, Cerni FA,

Oliveira IS, Balenzuela $C$,

Alexandre-Silva GM, Zoccal KF, Reis MB, Wiezel GA, Peigneur S,

Pinheiro-Júnior EL, Tytgat J,

Cunha TM, Quinton L, Faccioli LH, Arantes EC, Zottich $U$ and Pucca MB

(2020) Pioneering Study on

Rhopalurus crassicauda Scorpion Venom: Isolation and Characterization of the Major Toxin and Hyaluronidase.

Front. Immunol. 11:2011.

doi: 10.3389/fimmu.2020.02011

\title{
Pioneering Study on Rhopalurus crassicauda Scorpion Venom: Isolation and Characterization of the Major Toxin and Hyaluronidase
}

Caio B. Abreu ${ }^{1 t}$, Karla C. F. Bordon ${ }^{2 t}$, Felipe A. Cerni' ${ }^{2}$, Isadora S. Oliveira ${ }^{2}$, Carla Balenzuela', Gabriel M. Alexandre-Silva', Karina F. Zoccal' ${ }^{3}$, Mouzarllem B. Reis ${ }^{3,4}$, Gisele A. Wiezel ${ }^{2}$, Steve Peigneur ${ }^{5}$, Ernesto L. Pinheiro-Júnior ${ }^{5}$, Jan Tytgat ${ }^{5}$, Tiago M. Cunha ${ }^{6}$, Loic Quinton ${ }^{7}$, Lúcia H. Faccioli' ${ }^{4}$ Eliane C. Arantes ${ }^{2}$, Umberto Zottich ${ }^{1}$ and Manuela B. Pucca ${ }^{1 *}$

'Medical School, Federal University of Roraima, Boa Vista, Brazil, ${ }^{2}$ Department of BioMolecular Sciences, School of Pharmaceutical Sciences of Ribeirão Preto, University of São Paulo, São Paulo, Brazil, ${ }^{3}$ Barão de Mauá University Center, Ribeirão Preto, Brazil, ${ }^{4}$ Department of Clinical Analysis, Toxicology and Food Science, School of Pharmaceutical Sciences of Ribeirão Preto, University of São Paulo, São Paulo, Brazil, ${ }^{5}$ Toxicology and Pharmacology, KU Leuven, Leuven, Belgium, ${ }^{6}$ Department of Pharmacology, Ribeirão Preto Medical School, University of São Paulo, São Paulo, Brazil, ${ }^{7}$ Mass

Spectrometry Laboratory, MolSys Research Unit, Liège Université, Liège, Belgium

Scorpionism is responsible for most accidents involving venomous animals in Brazil, which leads to severe symptoms that can evolve to death. Scorpion venoms consist of complexes cocktails, including peptides, proteins, and non-protein compounds, making separation and purification procedures extremely difficult and time-consuming. Scorpion toxins target different biological systems and can be used in basic science, for clinical, and biotechnological applications. This study is the first to explore the venom content of the unexplored scorpion species Rhopalurus crassicauda, which inhabits exclusively the northernmost state of Brazil, named Roraima, and southern region of Guyana. Here, we pioneer the fractionation of the $R$. crassicauda venom and isolated and characterized a novel scorpion beta-neurotoxin, designated Rc1, and a monomeric hyaluronidase. R. crassicauda venom and Rc1 (6,882 Da) demonstrated pro-inflammatory activities in vitro and a nociceptive response in vivo. Moreover, Rc1 toxin showed specificity for activating $\mathrm{Na}_{v} 1.4, \mathrm{Na}_{v} 1.6$, and $\mathrm{BgNa}_{v} 1$ voltage-gated ion channels. This study also represents a new perspective for the treatment of envenomings in Roraima, since the Brazilian scorpion and arachnid antivenoms were not able to recognize $R$. crassicauda venom and its fractions (with exception of hyaluronidase). Our work provides useful insights for the first understanding of the painful sting and pro-inflammatory effects associated with $R$. crassicauda envenomings.

Keywords: scorpion venom, Rhopalurus crassicauda, toxin, electrophysiology, nociception, neurotoxin, proinflammatory toxin

\section{INTRODUCTION}

Venomous animals possess the capacity to develop a wide array of compounds with different biological effects inside a specialized apparatus to inject the venom into the preys $(1,2)$. In Brazil, accidents caused by venomous animals are a frequent neglected disease, with blind spots regarding general education and proper approach in most countries $(3,4)$. Scorpionism is included in this 
scenario, in which Tityus serrulatus species is responsible for most of the accidents in the country, reaching numbers of over 100,000 reports in 2017 (5-7). In spite hereof, there are still many neglected accidents caused by other scorpion species in the Brazilian biome (6), such as the scorpion Rhopalurus crassicauda, which make the data underestimated.

Described in 1947 (8), R. crassicauda species inhabits exclusively the northernmost state of Brazil named Roraima and southern region of Guyana (3), although species of the same genus are found in other regions of the country $(9,10)$. However, R. crassicauda taxonomic is complex and controversial. For instance, the enigmatic species was also referred as $R$. pinto $i$ in spite of the deep differences between both original descriptions. Further, it was treated as a subspecies of R. laticauda, which was restored as $R$. crassicauda as the valid species (11). Recently, the species was again considered a $R$. laticauda species (12). In this study we will keep the original taxonomic classification endorsed by Lourenço (2002) - R. crassicauda (11), since the researcher performed R. crassicauda collections around Boa Vista, Roraima, where actual samplings for the present work were conducted.

Albeit underreported accidents are a problem throughout Brazil, Roraima stands out for its scarce investment in research, the high number of indigenous people (more than $40 \%$ of the state is considered indigenous areas), and the vast number of Venezuelan migrants (3). Moreover, Roraima is a very poor region and has been overlooked by the Brazilian government and richest states (i.e., located mainly in south and southeast regions). Although the envenomings caused by scorpions in Roraima have been increasing in wide scale $(32,139$, and 288 cases in 2007, 2017, and 2019, respectively) (13), human envenomings caused by $R$. crassicauda and its venom composition remain unexplored (unmatched data in the main academic databases), even though more than 70 years passed since the species description.

Scorpion venoms can trigger several clinical effects and their toxins can target different biological systems (5). Thus, several signs and symptoms can be observed in victims stung by scorpions such as pain, myosis, bradycardia, cardiac arrhythmias, arterial hypotension, increased lachrymal, nasal, salivary, pancreatic, gastric and bronchial secretions, diaphoresis, tremors, piloerection, and muscle spasms, increases blood amylase levels, mydriasis, cardiac arrhythmias, tachycardia, arterial hypertension, acute pulmonary edema, cardiac failure, and even circulatory shock following death (14-16). Concerning $R$. crassicauda, although there is no report about the signs and symptoms, physicians in Roraima have not faced severe intoxication by victims stung by this species, although intense pain and mild paresthesia are always reported by patients.

In Brazil, the use of specific antivenom is indicated to treat all severe scorpion envenomings $(5,17)$, and the antivenom administration is mandatory in case of envenoming in children under 7 years-old or adults, mainly elderly, with previous health problems such as hypertension and cardiovascular diseases. Nevertheless, besides all the potential adverse effects produced by horse-derived antivenoms (i.e., anaphylactic reaction and serum sickness), and the larger than necessary dose of equine antibodies (about $70 \%$ of the antibodies are considered unspecific) (18), the Brazilian scorpion antivenom is produced exclusively against
T. serrulatus species and could not be used to treat accidents caused by other scorpion genera (e.g., R. crassicauda), whilst there are more than 160 different documented scorpion species in the country (7). This study is the first one to explore the venom content of the neglected scorpion species $R$. crassicauda from an overlooked and poor state of Brazil - Roraima. In particular, an effort was made to isolate and characterize a novel scorpion neurotoxin ( $\mathrm{Rc} 1$ ), and a spreading factor (hyaluronidase) from its venom.

\section{RESULTS}

\section{Scorpions and Venom Milking}

A total of 23 specimens of $R$. crassicauda scorpions, collected in the region of Boa Vista (Figure 1), were kept in the vivarium for venom milking. In order to standardize venom milking, our research group successfully built a restraining electrical device coupled to a dimmer potentiometer. After different electrical stimulation tests in the scorpion telson, the voltage of $18 \mathrm{~V}$ proved to be the best and thus suitable for R. crassicauda milking. During the initial stages of electrical stimulation, a colorless, watery venom was obtained; subsequently, the milked venom was a viscous fluid. From a total of 115 milky scorpions (one milky droplet extracted), $9.2 \mathrm{mg}$ of proteins was estimated in the soluble crude venom, corresponding to an average of $80 \mu \mathrm{g}$ of proteins per scorpion.

\section{Venom Fractionation and Enzymatic Activities}

To isolate the toxins, the $R$. crassicauda venom was submitted to reversed-phase fast protein liquid chromatography (RP-FPLC) on a C18 column $(10 \times 250 \mathrm{~mm})$ and the major peak (fraction P8, Figure 2A) was re-chromatographed on a different C18 column $(2.1 \times 250 \mathrm{~mm}$; Figure $2 B)$. The resulting pure toxin, named Rc1, represented $24 \%$ of the total protein of the soluble crude venom.

A Tricine-SDS-PAGE (16.5\%) electrophoresis was used to evaluate the complexity of the components present in $R$. crassicauda venom compared to $T$. serrulatus venom, as well as the purity profile of the eluted fractions (Figure 3). Nonreduced venom and peak 9 (P9) showed a single translucent band of $\sim 45 \mathrm{kDa}$ in the hyaluronan-based gel (Figure 3, lanes 20 and 21), indicanting hyaluronidase activity. On the other hand, under reduction conditions, P9 presented a molecular mass of $\sim 54 \mathrm{kDa}$ (Figure 3, lane 14). The major peak $\mathrm{P} 8$ revealed a unique protein band of $\sim 6.5 \mathrm{kDa}$ (Figure 3, lane 5).

Non-enzymatic activities of PDE and $\mathrm{PLA}_{2}$ were detected on $R$. crassicauda venom in the tested concentrations (5 and $65 \mu \mathrm{g} /$ well, respectively, data not shown).

\section{Molecular Mass and Sequence of Rc1}

The mass spectrum of Rcl showed an average ion $m / z$ 6,883.3 $\mathrm{Da}$ and the ion $m / z 3,443.1 \mathrm{Da}\left[(\mathrm{M}+2 \mathrm{H})^{2+}\right.$; Figure 4A]. The first $27 \mathrm{~N}$-terminal amino acids from Rcl were determined by Edman degradation method as KGGYPVDSKGCKISCVINNEYCSRDCT. In addition, Rc1 


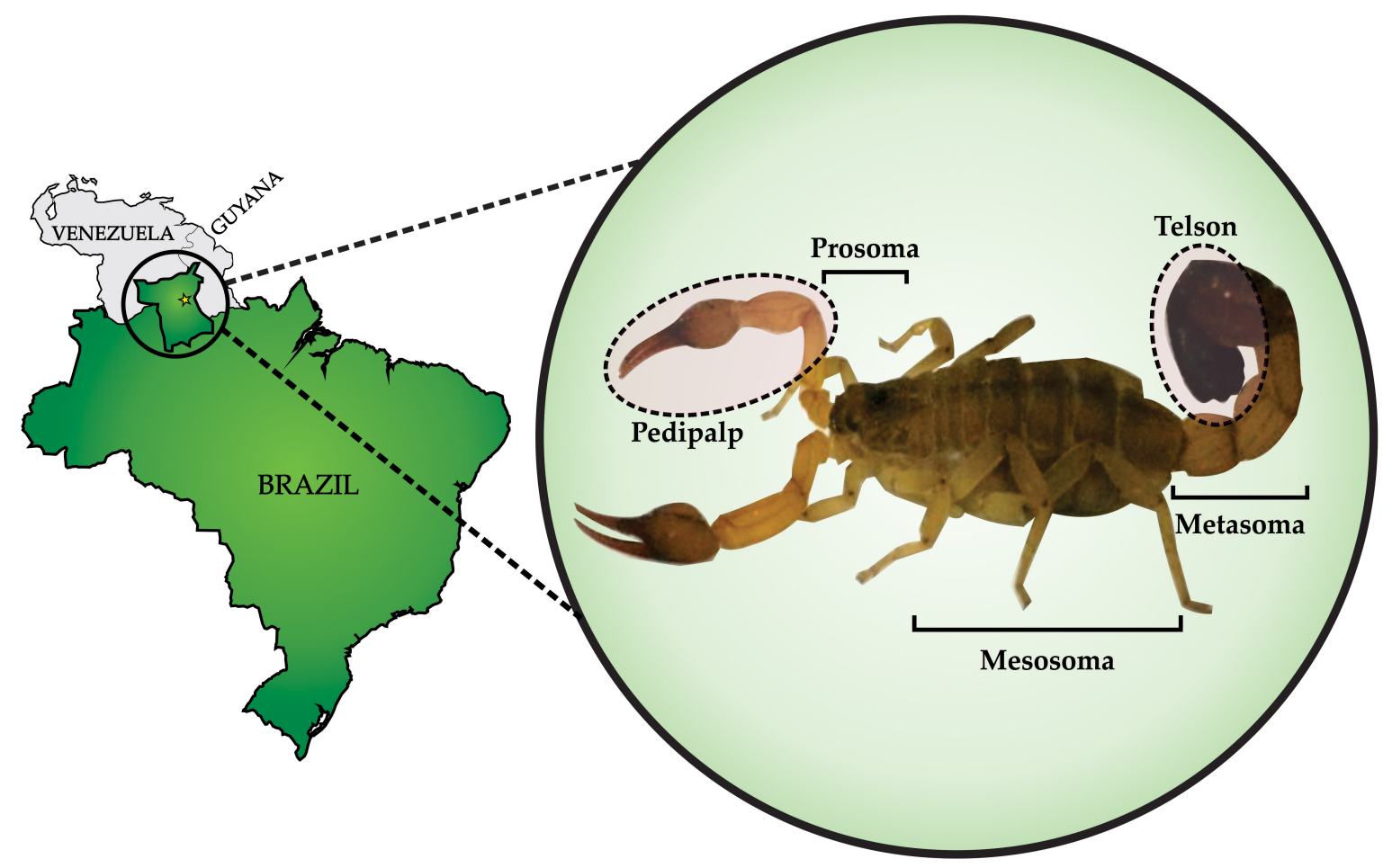

FIGURE 1 | Rhopalurus crassicauda: collection and morphology. Left panel shows Roraima, the northernmost state of Brazil. The yellow star indicates the capital city of the state, Boa Vista, where R. crassicauda scorpions were collected. Zoom view in the right panel shows the R. crassicauda species (scorpion length $10 \mathrm{~cm}$ ). Photo taken of a specimen kept in the scorpion vivarium of the research group.

internal peptides (Supplementary Table 1) were determined by de novo sequencing resulting in a sequence coverage of $\sim 80 \%$, considering the peptides masses in comparison to Rc1 molecular mass determined by matrix-assisted laser desorption/ionization (MALDI)-time of flight (TOF; Figure 4A). Seven Cys conserved residues were recovered from 8 estimated Cys residues. The total sequence obtained for Rc1 (the protein sequence data will appear in UniProt Knowledgebase under the accession number C0HLR6) presented 60\% identity with Css9 beta-neurotoxin from Centruroides suffusus (Figure 4B).

\section{Antivenom Cross-Reactivity}

The Brazilian scorpion (ScA) and arachnid (ArA) antivenoms were not able to recognize the soluble crude venom of $R$. crassicauda (Figures 5A,B). However, ScA was able to recognize venom fraction $\mathrm{P9}$, which presents hyaluronidase (Figure 5C).

\section{Venom and Major Toxin Effects}

Both R. crassicauda venom and Rc1 toxin (100 and $50 \mu \mathrm{g} / \mathrm{mL}$, respectively) demonstrated no cytotoxic effects on J774.1 cells (data not shown).

Rhopalurus crassicauda venom $(100 \mu \mathrm{g} / \mathrm{mL})$ increased IL6 production (Figure 6B), whereas Rcl stimulated TNF- $\alpha$ production. Interestingly, Rcl was able to increase two-fold the TNF- $\alpha$ levels when compared to Ts1 (Figure 6A), being a potent inflammatory toxin. Moreover, NF-kB signaling pathway was activated by $R$. crassicauda venom and Rcl stimuli, as observed with $T$. serrulatus venom and Ts 1 , indicating that both scorpion venoms, and major toxins activate intracellular pro-inflammatory pathways (Figure 7).

Rc1 activity was also tested on 6 different voltage-gated sodium channels expressed in Xenopus laevis oocytes. It was investigated if $\mathrm{Rcl}$, at a concentration of $1 \mu \mathrm{M}$, could modulate the voltage dependence of the steady-state activation and inactivation curves. Rcl altered the activation process of Nav1.4, Nav1.6 channels, and of the insect channels $\mathrm{BgNa}_{\mathrm{V}} 1$ (Figure 8). Application of $1 \mu \mathrm{M} \mathrm{Rcl}$ shifted the midpoint of activation from $-29.7 \pm 0.1 \mathrm{mV}$ in control to $-48.5 \pm 0.5 \mathrm{mV}$ for Nav1.6 channels $(n=4)$. For BgNav1 channels, an alteration of the $\mathrm{V}_{1 / 2}$ from $-37.7 \pm 0.3 \mathrm{mV}$ to $-64.8 \pm 0.5 \mathrm{mV}$ after application of Rc1 was observed $(n=6)$. For Nav1.4 channels, a minor but still significant modulation of activation was noted since $\mathrm{V}_{1 / 2}$ values yielded $-22.9 \pm 0.1 \mathrm{mV}$ and $-27.2 \pm 0.2 \mathrm{mV}$ in control and in presence of Rc1, respectively. The steady-state inactivation curves were not significantly altered in the presence of Rc1. Rc1 did not show activity on Nav1.1, Nav1.2, and Nav1.5 channels (Figure 8).

In vivo, although $R$. crassicauda induced a significant increase in mice paw licking and lifting during the first $15 \mathrm{~min}$ (in all tested concentrations), the spontaneous nociception behavior was considerably lower when compared to T. serrulatus venom (Figure 9A). The same was observed to Rc1 toxin, which needs four-fold more toxin to induce similar nociceptive behavior of Ts1 (Figure 9B). 


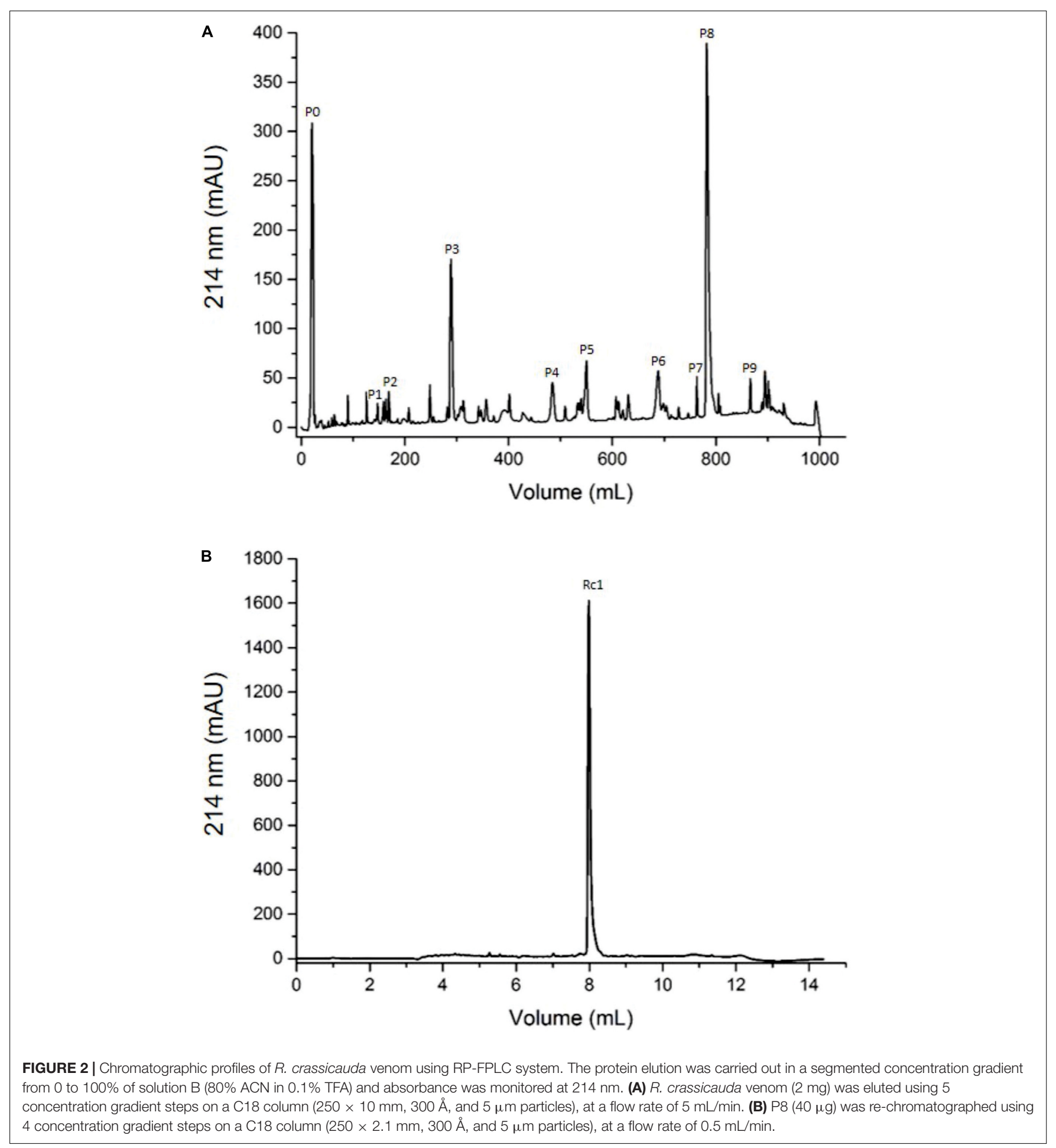

\section{DISCUSSION}

A single venom can contain up to several hundred different components producing diverse pathophysiological effects (19). Thus, studies focusing on the development of new drugs based on novel toxins remain valuable today. In addition, the understanding of a venom content can also elucidate local human envenomings and improve the efficacy of antivenom manufacture $(20,21)$. Although uncountable venomous species and their venoms have been over studied so far, $R$. crassicauda venom remains still unexplored (11).

In this study, the electrical method of venom extraction appears to be safe and successful for specimens of $R$. crassicauda, i.e., permanent injuries were not noticed neither immediately 


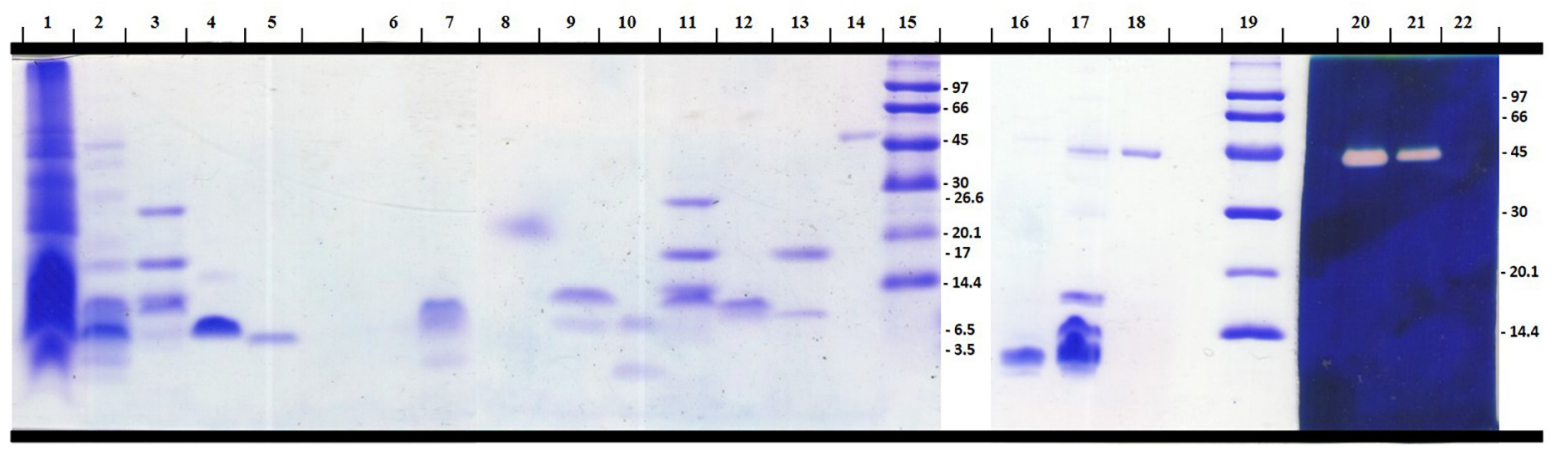

FIGURE 3 | Electrophoretical profile of $R$. crassicauda venom and fractions. Tris-tricine-SDS-PAGE (16.5\%) under reducing (Lanes 1-15) and non-reducing (Lanes 16-22) conditions. Lanes 16-22 were incorporated with hyaluronan before gel polymerization. Lanes 1, 16, and 22: T. serrulatus venom (18, 16, and $5 \mu \mathrm{g}$, respectively). Lanes 2, 17, and 21: $R$. crassicauda venom (18, 5, and $5 \mu \mathrm{g}$, respectively). Lanes 3 and 11: molecular mass markers (Sigma M3546). Lanes 15 and 19: molecular mass markers (GE Healthcare 17-0446-01). Lanes 4 and 5: Ts1 and Rc1 (P8), respectively (2 $\mu$ g). Lanes: 6: P1; 7: P2; 8: P3; 9: P4; 10: P5; 12: P6; 13: P7 (all $2 \mu \mathrm{g})$. Lanes 14, 18, and 20: P9 $(2 \mu \mathrm{g})$. Lanes 1-19 were stained with PlusOne Coomassie Blue PhastGel ${ }^{\circledR}$ R-350. Lanes 20-22 were stained with Stains-all for evaluation of the hyaluronidase activity.

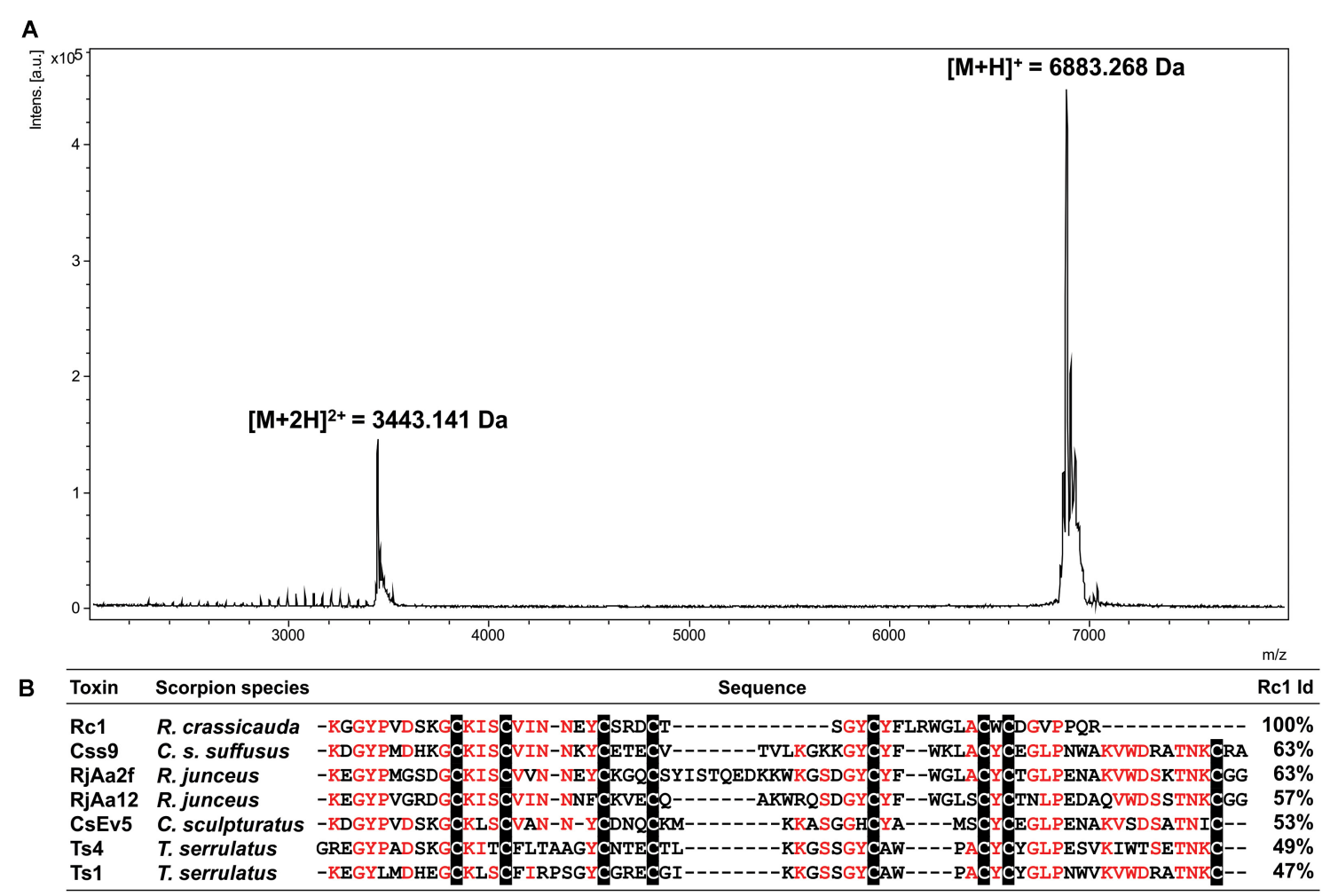

FIGURE 4 | (A) Mass spectrum of Rc1 obtained by MALDI-TOF mass spectrometry in a positive linear ionization mode using DHB matrix. (B) Sequence alignments of the Rc1 partial sequence (B3EWP2) with other beta-neurotoxins. Css9 (Centruroides suffusus, F1CGT6), CsEv5 (C. sculpturatus, P58779), Ts4 (T. serrulatus, P45669), Ts1 (T. serrulatus, P15226), RjAa2f (R. junceus, E7CLP6), and RjAa12 (R. junceus, E7CLN6). Conserved residues are in red and Cys residues are shaded in black. Alignment was generated by Clustal Omega server. Identity percentage considered among the aligned residues.

nor within 3 weeks after the milking. The $18 \mathrm{~V}$ required for $R$. crassicauda milking demonstrated to be higher than that used in the literature for T. serrulatus venom extraction (12 V) (22). The thickening of $R$. crassicauda metasoma probably explains the need for a higher tension (the prefix "crassi" means tick or fat in Latin, hence crassicauda denotes fat-tail).
The purification procedure of $R$. crassicauda venom was able to provide its pure major toxin Rc1 (P8) and hyaluronidase (P9). MS/MS analysis and N-terminal sequencing enabled to cover $\sim 80 \%$ of Rcl primary sequence. Gaps are due to possible basic regions in $\mathrm{Rcl}$ over digested by trypsin hindering peptide identification. It is interesting to note the presence of small 
A

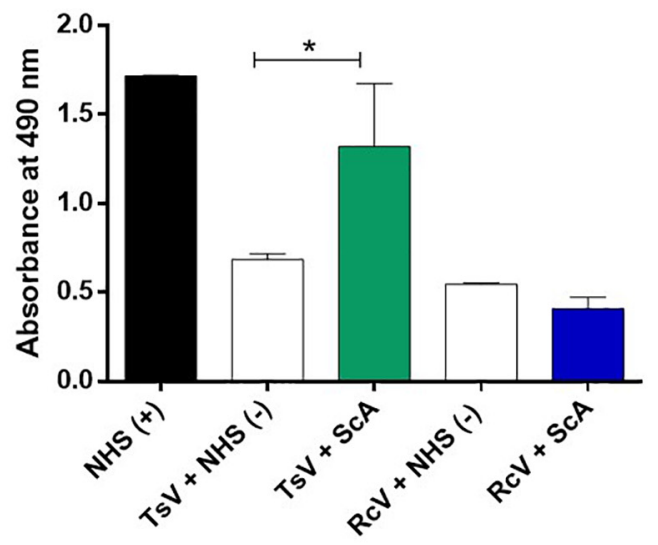

B

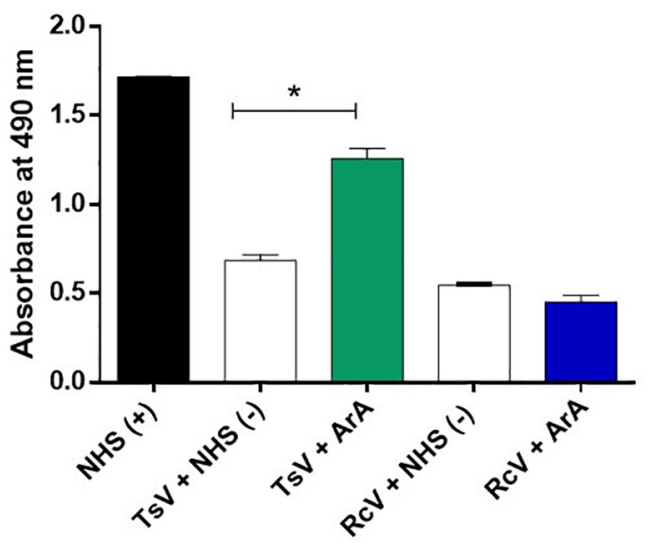

C

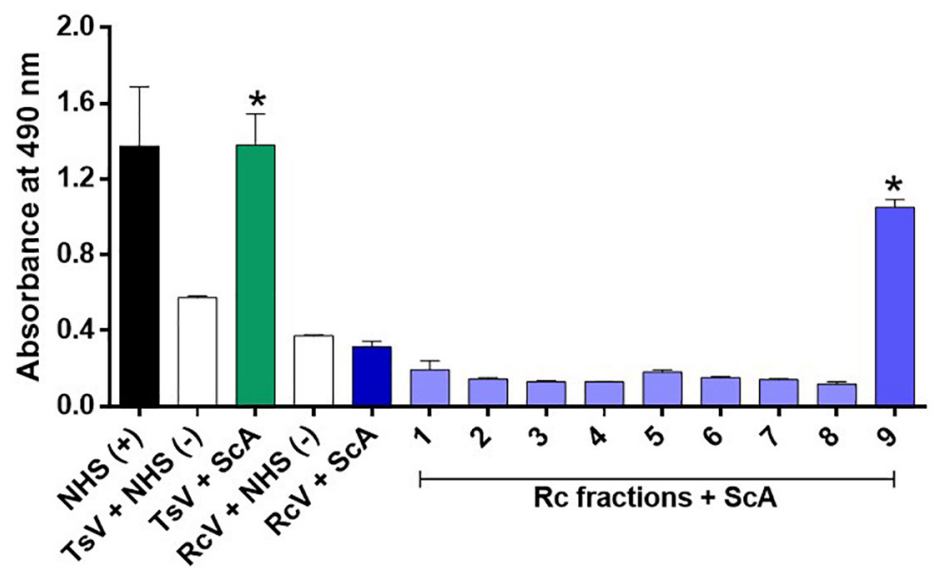

FIGURE 5 | Immunorecognition of R. crassicauda venom by Brazilian scorpion and arachnid antivenoms. (A) Scorpion antivenom. (B) Arachnid antivenom.

(C) Scorpion antivenom and $R$. crassicauda fractions. The 96-well plates were coated with $2 \mu \mathrm{g}$ of $R$. crassicauda venom or fractions (1-9) diluted in a solution of $0.05 \mathrm{M}$ carbonate-bicarbonate buffer (pH 9.6). Positive controls (+) were performed with wells coated with non-immune horse serum or TsV, and negative controls $(-)$ were performed by replacing antivenoms with non-immune horse serum. Absorbance was measured at $490 \mathrm{~nm}$. NHS: non-immune horse serum. TsV,

T. serrulatus venom; ScA, scorpion antivenom; ArA, arachnid antivenom; and RcV, R. crassicauda venom. Results are presented as mean $\pm S D(n=3)$, which were analyzed by ANOVA followed by Tukey's multiple comparison test ( ${ }^{*} p<0.05$, when compared to the negative respective controls).

A

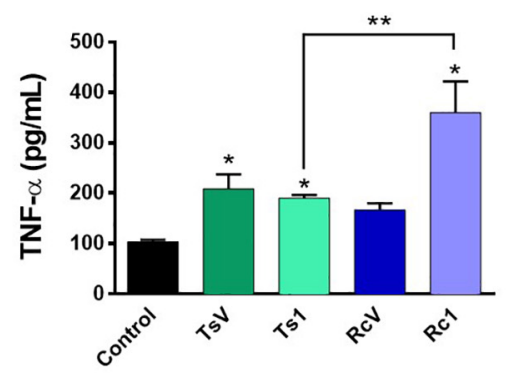

B

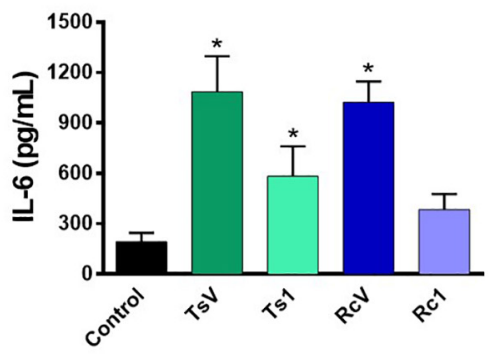

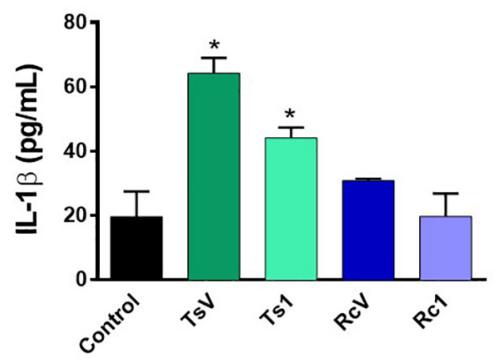

FIGURE 6 | Effect of $R$. crassicauda venom and the major toxin on cytokine levels. J774.1 cells were stimulated with $R$. crassicauda venom (100 $\mu \mathrm{g} / \mathrm{mL})$ or Rc1 toxin $(50 \mu \mathrm{g} / \mathrm{mL})$ for $24 \mathrm{~h}$. As negative control, stimuli with T. serrulatus venom (100 $\mu \mathrm{g} / \mathrm{mL})$, Ts1 $(50 \mu \mathrm{g} / \mathrm{mL})$, and unstimulated cells were used. (A) TNF- $\alpha$. (B) IL-6. (C) IL-1 $\beta$. TsV: T. serrulatus venom. RcV: R. crassicauda venom. Results are presented as mean $\pm \mathrm{SD}(n=4)$, which were analyzed by ANOVA followed by Tukey's post hoc test ( ${ }^{*} p<0.05$ when compared to controls; ${ }^{* *} p<0.001$ when compared to Ts1). 


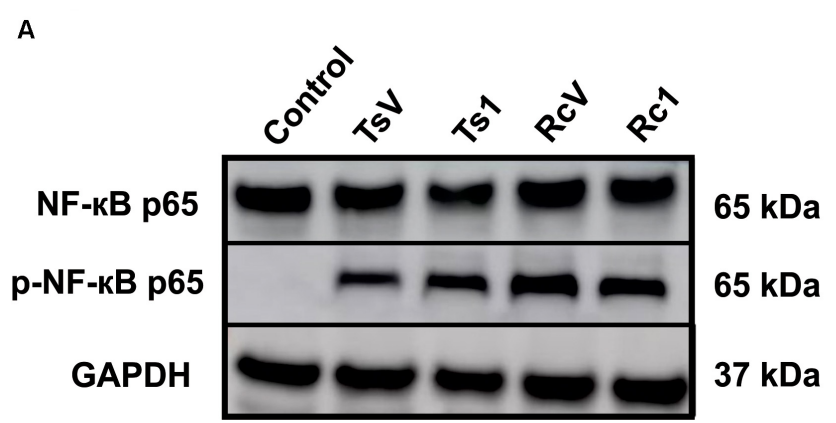

B

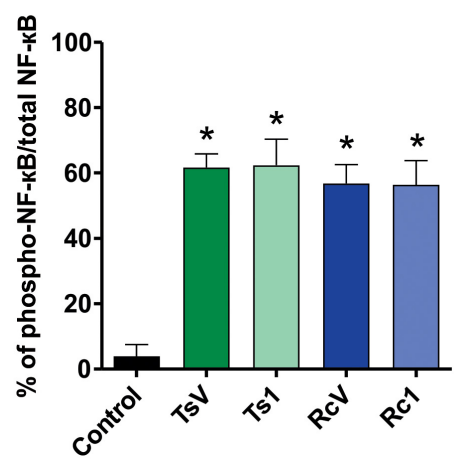

FIGURE 7 | Effect of $R$. crassicauda venom and the major toxin on the NF-kB signaling pathway. (A) Western blot of phospho-NF-kB p65 and NF-kB p65 proteins (GAPDH as an internal control). Lane 1 represents control (medium) and lanes 2-5 represent TsV, Ts1, RcV, and Rc1, respectively. (B) Percentage of expression of the target protein against the reference protein as quantified by band densitometry. TsV: T. serrulatus venom. RcV: R. crassicauda venom. Results are presented as mean $\pm \operatorname{SD}(n=4)$, which were analyzed by ANOVA followed by Tukey's post hoc test $\left({ }^{*} p<0.001\right.$ when compared to control).

fragments from the same peptide (Supplementary Table 1) which indicates that Rcl may undergo a proteolytic cleavage by peptidases within the venom gland. In fact, peptidases have been already detected in scorpion venom glands such as those from Mesobuthus eupeus (ENA| EF442061.1) and Hadrurus gertschi (23). This process might be related to the processing of intracellular proteins as well as to increase venom complexity by producing different proteins/peptides from one single gene (23-26). A mechanism of post-splitting (a post-translational processing) was suggested to Ts 19 from T. serrulatus, resulting on fragments with split functional activity (26). Moreover, toxin proteolysis is not uncommon to occur in scorpion venoms (24) and a similar fact have also been described in the venom from the ant Neoponera villosa (27).

Unfortunately, we could not explore the hyaluronidase sequence due to the low quantity of pure enzyme recovery. Hyaluronidases facilitate the spreading of toxins into the tissues of the prey/victims, since these enzymes hydrolyze hyaluronan of the interstitial matrix $(28,29)$. P9 is a monomeric hyaluronidase of $54 \mathrm{kDa}$ (reduced) and $45 \mathrm{kDa}$ (non-reduced), as estimated by Tris-Tricine-SDS-PAGE. The observed molecular mass is within the range from 45 to $82 \mathrm{kDa}$ described for scorpion venom hyaluronidases $(30,31)$. Although there are about 2,200 scorpion species known in the world (32), there are only 12 scorpion hyaluronidases primary sequences deposited in the databanks and 5 enzyme isolation reports (from Heterometrus fulvipes, T. serrulatus, Palamneus gravimanus, T. stigmurus, and Mesobuthus martensii venoms) (28). Our study is the first one to isolate a hyaluronidase from the scorpion genus Rhopalurus, as evidenced as a single band by Tris-Tricine-SDSPAGE containing hyaluronan.

On the other hand, our study did not detect the phosphodiesterase (PDE) activity in Rc venom. PDEs are exonucleases, possessing the ability to cleave DNA and RNA, as well as other fundamental molecules for physiological processes such as ATP and cAMP $(33,34)$. These proteins have a molecular mass between 90 and $160 \mathrm{kDa}$ and are widely distributed in snake venoms, although they are commonly found in a few amount on them $(35,36)$. So far, there are no reports describing PDEs in scorpion venoms. Indeed, the electrophoretic profile of Rc venom did not reveal proteins with high molecular mass over $54 \mathrm{kDa}$, which corresponds to hyaluronidase.

As such Rhopalurus junceus (37), R. crassicauda venom showed no $\mathrm{PLA}_{2}$ activity. Instead Rodríguez-Ravelo et al., using the same species ( $R$. junceus) and mass spectrometry analysis, demonstrated that the scorpions from La Poa area, collected in the humid area of Baracoa, Guantanamo Province, showed the presence of phospholipase $\mathrm{A}_{2}$ (molecular mass within the range from 14 to $19 \mathrm{kDa}$ ) (38). The other scorpion species in which this enzyme activity was detected are Pandinus imperator (39, 40), Anuroctonus phaiodactylus (41), Scorpio maurus palmatus (42), Opisthacanthus cayaporum (43), H. fulvipes (44), and H. laoticus (45).

Rc1 exhibited an identity score in the range of $46-60 \%$ with scorpion $\beta$-neurotoxins from C. suffusus, Centruroides sculpturatus, and T. serrulatus. $\beta$-scorpion toxins bind at a socalled "site-4" of Nav channels, and shift the voltage dependence of $\mathrm{Na}_{V}$ channel activation toward more negative potentials, promoting spontaneous and repetitive firing (46). Scorpion toxins targeting voltage-gated sodium channels (NaTx) are, in general, composed of 60-76 amino acids cross-linked by four disulfide bounds and are known as long-chain toxins (46). Rc1 presents the positively charged Lys at positions 1 and 12, but, strikingly, it does not show a negatively charged Glu at position 2. All these three residues were shown as determinants of the specificity of $\beta$-toxins $(47,48)$. In any case, the Rcl electrophysiological findings for the first time reveal the neurotoxic effects of the main Roraima's scorpion venom, which can explain some of the symptoms observed after local envenomings, such as local inflammation and pain.

Indeed, this is the pioneer study showing that $R$. crassicauda venom presents pro-inflammatory activities. The in vitro assays demonstrated that this species venom increases levels of IL- 6 and that the main toxin Rcl outstanding increases TNF- $\alpha$ levels. Both 
A
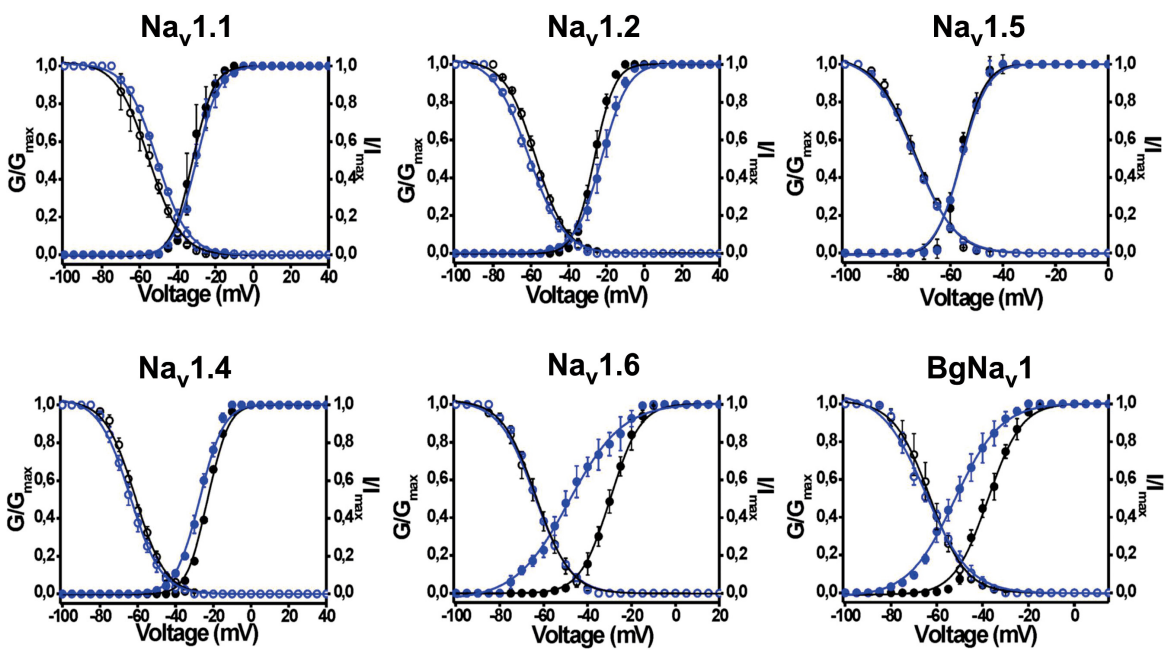

$\mathrm{BgNa}_{\mathrm{v}} 1$

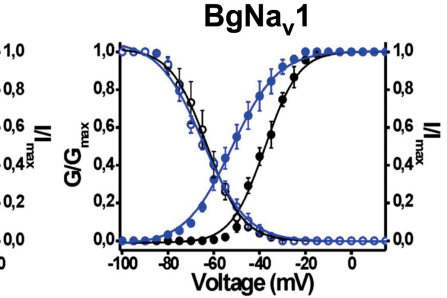

B
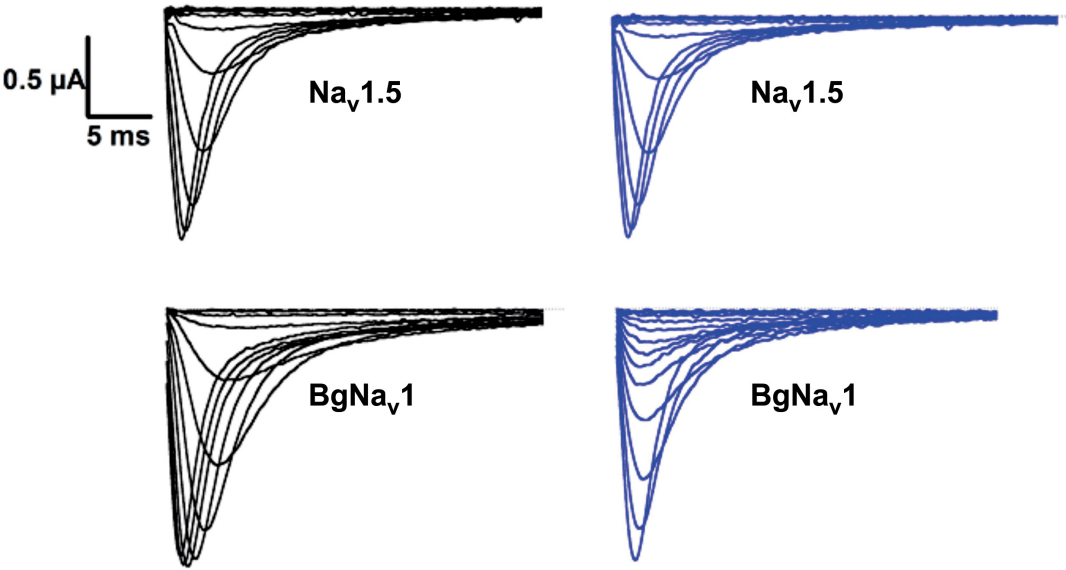

$\mathrm{Na}_{\mathrm{v}} \mathbf{1 . 5}$

C

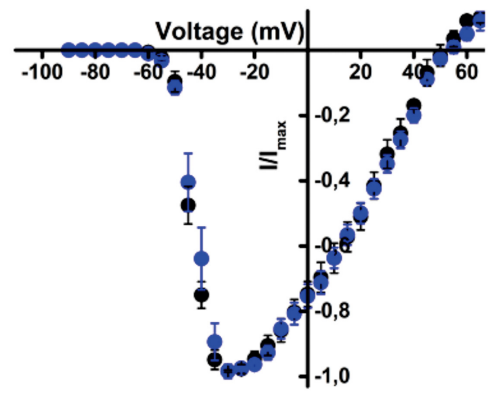

$\mathrm{BgNa}_{\mathrm{v}}{ }^{1}$

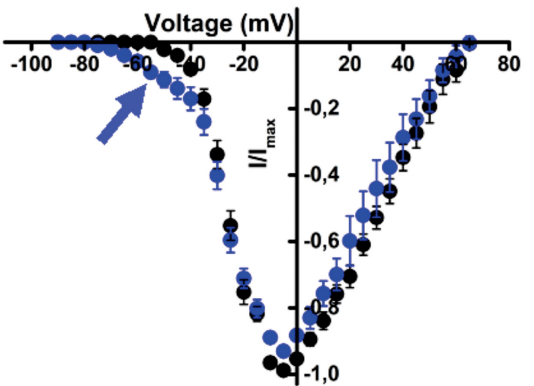

FIGURE 8 | Electrophysiological effects of the major toxin on voltage-gated sodium channels. (A) Effects of Rc1 on the voltage dependence of steady-state activation and inactivation curves under control conditions (black symbols) and after the addition of $1 \mu \mathrm{M}$ of Rc1 (blue symbols), $n=4$ cells \pm SEM. (B) Current traces of Nav1.5 (non-effect) and BgNav channels in control (black) and in the presence of Rc1 channels (blue). (C) IV curves in control (black) and after application of Rc1 for Nav1.5 (non-effect) and BgNav1 channels. 
A

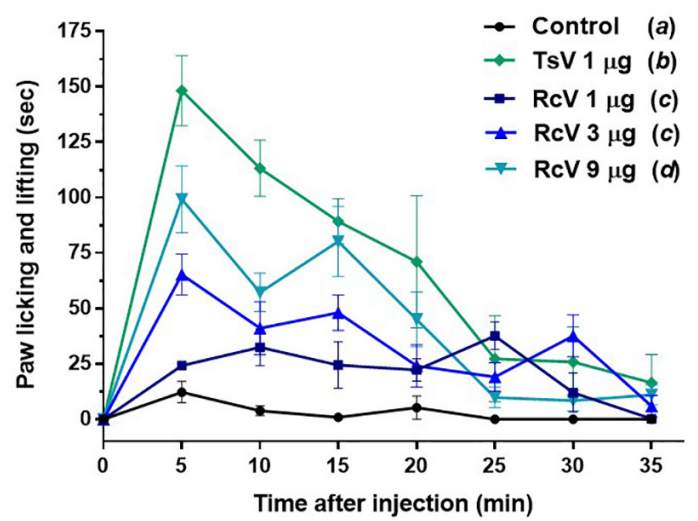

B

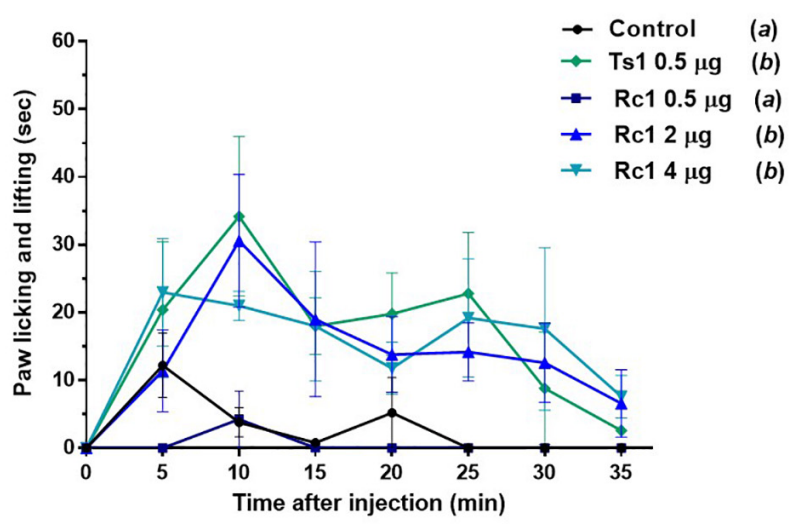

FIGURE 9 | Spontaneous nociception induced by $R$. crassicauda venom and the major toxin. Nociception was assessed by recording the time course of paw licking and lifting behavior after intraplanar (ipl) injections of RcV venom (A) or Rc1 (B) into C57BL/6 mice right hind paw. T. serrulatus venom and its main toxin (Ts1) were used as controls. TsV: T. serrulatus venom. RcV: $R$. crassicauda venom. Data are presented as the mean $\pm \mathrm{SD}(n=5)$, which were analyzed by Two-way ANOVA followed by Tukey's post hoc test. Same and different letters represent, respectively, no and statistically significant differences between groups.

IL-6 and TNF- $\alpha$ are cytokines featuring pleiotropic activities. For instance, they can induce synthesis of acute phase proteins, stimulate antibody production and effector T-cell development, as well as elevation of body temperature $(49,50)$. On the other hand, in the tested concentrations, neither RcV nor Rc1 increased IL-1 $\beta$, although high levels of this pro-inflammatory cytokine had previous been documented both in patients envenomated by T. serrulatus venom (51) and in vivo using T. serrulatus Ts6 toxin (52). In addition, our study demonstrated that both $R$. crassicauda venom and $\mathrm{Rcl}$ can also activate the NF-kB signaling pathway. This result was consistent with previously reported results for T. serrulatus venom and toxins (5,53-57), thus we supposed that activation of the NF-kB signaling pathway could be one important mechanism of enhancing the immune responses from several scorpion envenomings (53).

The NF-kB signaling pathway that mediates inflammatory responses is the canonical pathway, which is well described elsewhere $(58,59)$. Scorpion toxins, such as Ts1 (a $\beta$-toxin like $\mathrm{Rc} 1$ ), are known to be recognized by toll like receptors 2 (TLR2), 4 (TLR4), and CD14, resulting in the activation of NF-kB canonical pathway, which culminates in the production of inflammatory mediators such as cytokines (e.g., IL-6 and TNF- $\alpha$ ) and lipid mediators (e.g., $\mathrm{PGE}_{2}$ and $\mathrm{LTB}_{4}$ ) (54).

Moreover, both $\mathrm{RcV}$ and $\mathrm{Rcl}$ were not cytotoxic to macrophages in the tested concentration $(100 \mu \mathrm{g} / \mathrm{mL})$. DíazGarcía et al. had demonstrated that different fractions of R. junceus venom were cytotoxic to A549 and MRC-5 lung cell lines; however, in that study, the authors tested high venom concentrations up to $600 \mu \mathrm{g} / \mathrm{mL}$ (37). In 2019, the same research group demonstrated that $R$. junceus venom inhibited the tumor progression in F3II bearing-mice in a dose-dependent manner (60). As such, $R$. princeps venom has also been explored as an anticancer agent (61).

Based on the greater number of neurotoxins affecting $\mathrm{Nav}$ channels and the increase of pro-inflammatory mediators, scorpion venoms can modulate the nociceptive response $(5,62)$. Factually, scorpions are well-known to cause immediate and localized painful stings, which can be classified as mild, moderate, severe, and very severe, being severe defined as a pain greater than that of a bee sting or equivalent $(63,64)$. Our studies demonstrated that both $R$. crassicauda venom as well as the toxin Rc1 are able to induce hypernociceptive response in mice, although to a lesser extend when compared to $T$. serrulatus venom and toxin. The peripheral sodium channels $\mathrm{Na}_{\mathrm{v}} 1.3$, $\mathrm{Na}_{\mathrm{v}} 1.6, \mathrm{Na}_{\mathrm{v}} 1.7, \mathrm{Na}_{\mathrm{v}} 1.8$, and $\mathrm{Na}_{\mathrm{v}} 1.9$ are mainly responsible for the pathophysiology of different pain syndromes $(65,66)$. Indeed, our electrophysiological studies conducted with isolated Rc1 toxin reveals that Rc1 alters the activation process of Nav1.4, Nav1.6, and BgNav1. Thus, the Rc1 action to Nav1.6 channels and the toxin-induced production of inflammatory mediators could explain the painful sting triggered by $R$. crassicauda envenoming. Finally, Rc1 also activated the insect channel BgNav from the cockroach Blattella germanica. Effects on insect ion channels are usually observed by scorpion-derived toxins, since insects are the preys of these animals, specially cockroaches, which are known to be their preferred diet (67). In fact, several studies demonstrate the potential of scorpion toxins to be used as insecticides (16, 68). Therefore, Rcl can be classified as a $\beta$-scorpion toxin targeting mammal and insect voltage-gated sodium channels, pro-inflammatory, and painful neurotoxin. There are few studies developed with other Rhopalurus species that corroborate with our results. For instance, García-Gómez et al. demonstrated that the venom of $R$. junceus produces a $\beta$-effect on sodium channels in F11 cell line (69). Nonetheless, different from our work, many of the literature studies explore scorpion toxins targeting potassium channels (Kvs) (70).

Regarding the cross-reactivity observed on ELISA assays, our results suggest that none of the antivenoms evaluated can recognize $R$. crassicauda venom, indicating selectivity of both antivenoms toward Tityus spp. venom components. According 
to the Butantan Institute pipeline, ScA is an antivenom specific to $T$. serrulatus scorpion venom, being indicated to the treatment of envenomings caused by scorpion from Tityus genus; while ArA is a polyvalent antivenom produced against $T$. serrulatus and two different spider venoms (i.e., Loxosceles and Phoneutria genera), being indicated for the treatment of envenomings caused by scorpions and spiders. Knowing that $T$. serrulatus scorpions are responsible for most and severe cases of envenomings in Brazil, the ability of the available antivenoms to crossneutralize venoms from others scorpion species is unknown, especially for accidents caused by another scorpion genus. In this study we did not identify antivenom cross-reactivity with $R$. crassicauda venom, although neurotoxins have been known to present a high degree of similarity $(46,71,72)$. However, when we analyzed each venom fraction, the scorpion antivenom was able to recognize fraction 9 (P9), which corresponds to hyaluronidase. Since this enzyme is also found in T. serrulatus venom (73) and the ScA is produced against this species venom, it is not surprising that the antivenom can cross-bind to the hyaluronidase from $R$. crassicauda venom. Moreover, most of venom-derived hyaluronidases have demonstrated high sequence identities, specially between the same animal class (28). For instance, T. serrulatus hyaluronidase shares a high identity with hyaluronidases from the venoms of C. sculpturatus (XP_023226974.1, 76\%), M. martensii (P86100.2, 72\%), and C. sculpturatus (XP_023244120.1, 54\%). The recognition of just one protein is definitely not enough to inhibit a venom cocktail toxicity and, although additional assays needs to be explored (i.e., in vivo lethality inhibition), it is unlikely that the scorpion antivenoms available in Brazil (ScA and ArA) could be used to treat severe cases of $R$. crassicauda envenomings in Roraima.

In conclusion, the present study pioneered the fractionation of $R$. crassicauda venom and successfully isolated and elucidated the major toxin, Rc1, and a hyaluronidase. Furthermore, this work provides useful insights for the first understanding of the painful sting and pro-inflammatory effects associated with $R$. crassicauda envenomings.

\section{MATERIALS AND METHODS}

\section{Scorpions and Venom Milking}

Rhopalurus crassicauda scorpions were collected in Boa Vista city (latitude $2^{\circ} 49^{\prime} 14.88^{\prime \prime}$ North and longitude $60^{\circ} 40^{\prime} 19.20^{\prime \prime}$ West), Roraima (the northernmost state of Brazil; Figure 1). The scorpions were usually caught in the wild, and adults ranging in size from 3 to 5 inches $(7-12 \mathrm{~cm})$ were kept in plastic boxes with adequate ventilation. The identification of species were performed through the taxonomic key previously described (11). The animals received water daily, were fed with crickets or cockroaches at least twice a month, and were kept at Medical School of Federal University of Roraima with authorization from the Brazilian Biodiversity Information and Authorization System (SISBIO, http://www.icmbio.gov.br/sisbio/) number 57491.

In total, 23 scorpions were fed 5 days prior to venom milking and each scorpion venom extraction were performed 5 times with intervals of 30-45 days. An extractor with a dimmer potentiometer was developed for this study. The scorpion was placed in the restraining device (an acrylic base with a metallic plate, and a plastic flexible band), the venom gland was firmly held with the pair of forceps, and the platinum electrode was placed against the distal somites. Electrical stimulation was applied for milking, using different electrical pulses (5 to $20 \mathrm{~V}$ ) during about 10-15 s. Venom was pooled and immediately stored at $-20^{\circ} \mathrm{C}$.

\section{Reversed-Phase Chromatography of R. crassicauda Venom and Tris-Tricine-SDS-PAGE}

The pooled desiccated $R$. crassicauda venom was dispersed in $0.5 \mathrm{~mL}$ of ultrapure water, centrifuged at $12,000 \mathrm{~g}, 4^{\circ} \mathrm{C}$, during $10 \mathrm{~min}$, for removal of insoluble mucus, resulting in the soluble crude venom (supernatant without mucus). The precipitate was resuspended twice under the same conditions and the supernatants were pooled. The protein concentration of the resulting soluble venom without mucus was estimated by NanoDrop ${ }^{\mathrm{TM}} 2000$ (Thermo Scientific, United States) using the extinction coefficient of 1.0. The soluble venom ( $2 \mathrm{mg}$ of proteins) was applied onto a C18 column $(10 \mathrm{~mm} \times 250 \mathrm{~mm}, 300 \AA, 5 \mu \mathrm{m}$ particles, Jupiter ${ }^{\circledR}$ Phenomenex, United States) equilibrated with $0.1 \%(\mathrm{~V} / \mathrm{V})$ trifluoroacetic acid (TFA). The samples were eluted with a step concentration gradient from 0 to $100 \%$ of solution B ( $80 \%$ acetonitrile, $\mathrm{ACN}$, in $0.1 \%$ TFA), at a flow rate of $5 \mathrm{~mL} / \mathrm{min}$. Absorbance was monitored at $214 \mathrm{~nm}$ by the FPLC Äkta Basic UPC-10 Frac-920 system (GE Healthcare, Uppsala, Sweden). The eluted fractions were lyophilized and stored at $-20^{\circ} \mathrm{C}$ until use. The major peak eluted in this chromatographic step was rechromatographed on another C18 column $(250 \times 2.1 \mathrm{~mm}$, $300 \AA$, $5 \mu \mathrm{m}$ particles, Jupiter ${ }^{\circledR}$ Phenomenex, United States), at a flow rate of $0.5 \mathrm{~mL} / \mathrm{min}$. The major isolated toxin was designated as Rc1 and submitted to next assays. Protein recovery of Rc1 was calculated by the relative peak area (the fraction peak area divided by total area of all the fractions in the chromatogram), considering both chromatograms. Soluble venoms (T. serrulatus venom, TsV, and RcV, $18 \mu \mathrm{g} /$ well), Ts1 ( $2 \mu \mathrm{g} /$ well), and the eluted chromatographic fractions (2 $\mu \mathrm{g} /$ well) were analyzed under reducing conditions by Tris Tricine Sodium Dodecyl Sulfate Polyacrylamide Gel Electrophoresis (Tris-Tricine-SDS-PAGE, 16.5\%) (74). The gels were stained with PlusOne Coomassie Blue PhastGel ${ }^{\circledR}$ R-350 (GE Healthcare, Uppsala, Sweden).

\section{Mass Spectrometry Analysis}

The molecular mass of Rcl $(0.65 \mu \mathrm{g})$ was determined by MALDI with TOF analyzer (RapifleX, Bruker Corporation, Billerica, MA, United States) controlled by flexControl 4.0 software (Bruker Corporation, Billerica, MA, United States). The parameters to obtain data were 10,000 laser shots per spectrum, $500 \mathrm{~Hz}$ laser frequency, and the instrument operating in linear positive mode. RapifleX was calibrated with Protein Calibration Standard I ( 4000 and 20000 Da, Bruker Corporation, Billerica, MA, United States). As matrix, $10 \mathrm{mg} / \mathrm{mL}$ solution of 2,5dihydroxybenzoic acid (DHB) was prepared in $\mathrm{ACN}$ and $0.1 \%$ TFA at $1: 1$ ratio. Data analysis was performed through 
the software flexAnalysis 3.4 (Bruker Corporation, Billerica, MA, United States).

Rc1 (1.5 $\mu \mathrm{g}$ ) was also reduced, alkylated, and digested with trypsin (Thermo Fisher Scientific Inc., Waltham, MA, United States) at 1:50 ratio, overnight, under $600 \mathrm{rpm}$ at $37^{\circ} \mathrm{C}$. Additionally, a second digestion was performed under similar conditions, but with a different ratio and time (1:100 and $3 \mathrm{~h}$, respectively). The reaction was stopped with $0.5 \%$ TFA and the sample desalted. Desalted tryptic peptides were solubilized in $50 \% \mathrm{ACN}$ and $0.1 \%$ TFA solution and analyzed by $\mathrm{nLC}-\mathrm{MS} / \mathrm{MS}$ in a Acquity UPLC ${ }^{\circledR}$ M-Class (Waters, Milford, MA, United States) coupled with a Q-Exactive ${ }^{\text {TM }}$ Plus Hybrid Quadrupole-Orbitrap ${ }^{\mathrm{TM}}$ Mass spectrometer (Thermo Scientific, Bremen, Germany). They were eluted at a flow rate of $0.6 \mathrm{nl} / \mathrm{min}$ using an ACN gradient (3-80\%) in $0.1 \%$ formic acid for $130 \mathrm{~min}$ and immediately submitted to mass spectrometry analysis. MS spectra $(400-1750 \mathrm{~m} / z)$ were acquired with high resolution $(70,000$ at $\mathrm{m} / z$ 200) and automatic gain control (AGC) target of $3 \mathrm{e} 6$. The twelve most intense ions were subsequently fragmented by HCD in a data-dependent mode. MS/MS spectra $(200-2000 \mathrm{~m} / z)$ were acquired with resolution of 17,500 (at $\mathrm{m} / z$ 200), normalized collision energy of 25, AGC target of $1 \mathrm{e} 5$ and isolation window of $\pm 2 \mathrm{~m} / z$. Ions with not assigned or +1 charge were not fragmented. Data were analyzed by PEAKS Studio 7 software (Bioinformatics Solutions Inc., Waterloo, Canada) and peptides sequences were generated by automatic de novo sequencing setting the following parameters: parent and fragment mass error tolerance (5.0 ppm and 0.015 Da, respectively) and fixed (cysteine carbamidomethylation) and variable (deamidation of Asn and Gln and oxidation of Met) modifications. All results were manually confirmed to exclude false positives and spectra were also manually investigated.

\section{$\mathbf{N}$-Terminal Sequencing}

The N-terminal sequence of Rc1 (33 $\mu \mathrm{g}$ ) was determined by Edman degradation (76), using an automated protein sequenator model PPSQ-33A (Shimadzu Co., Kyoto, Japan). The obtained sequence was compared with databases, searching similarities by using Basic Local Alignment Search Tool (BLAST) ${ }^{1}$.

\section{Hyaluronidase Activity}

The soluble venoms of $T$. serrulatus and $R$. crassicauda (5 $\mu \mathrm{g} /$ well) were analyzed under non-reducing conditions on Tris-Tricine-SDS-PAGE gel (74) and stained with PlusOne Coomassie Blue PhastGel ${ }^{\circledR}$ R-350. To detect the presence of hyaluronidase, a $16.5 \%$ separating gel containing $0.4 \mathrm{mg} / \mathrm{mL}$ hyaluronan, overlaid by a $5 \%$ stacking gel was used (67), which was stained with Stains-all (Sigma Chemical Co., St. Louis, United States) for evaluation of the hyaluronidase activity (76).

\section{Phosphodiesterase Activity}

Phosphodiesterase activity in $R$. crassicauda venom $(5 \mu \mathrm{g})$ was determined in a 96-well plate by using bis(p-nitrophenyl) phosphate as substrate, according to the protocol described by

${ }^{1}$ http://blast.ncbi.nlm.nih.gov/Blast.cgi
Björk (77) and modified by Valério et al. (78), with absorbance reading at $400 \mathrm{~nm}$. As a positive control, snake venom PDE $(0.75 \mu \mathrm{g})$ was used.

\section{Phospholipase $A_{2}$ Activity}

The phospholipase $\mathrm{A}_{2}\left(\mathrm{PLA}_{2}\right)$ activity was evaluated according to Habermann and Hardt (79). Briefly, one part of fresh egg yolk was mixed with 3 parts (V/V) of phosphate buffered saline (PBS) and centrifuged at $2,000 \mathrm{~g}$ for $10 \mathrm{~min}$. Then, $1.25 \mathrm{~mL}$ of the supernatant was added to a final $25 \mathrm{~mL}$-suspension containing $1.5 \%$ agar and $0.25 \mathrm{mM} \mathrm{CaCl}_{2}$ in PBS and poured into plastic Petri dishes $(90 \times 15 \mathrm{~mm}$, flat bottom $)$. After layer consolidation, cylindrical holes were performed using a $10 \mu \mathrm{L}$-pipet tip. Each well was charged with $50 \mu \mathrm{L}$ of $R$. crassicauda venom $(65 \mu \mathrm{g})$ and as controls bovine serum albumin $(300 \mu \mathrm{g})$ and Crotalus durissus terrificus venom $(10 \mu \mathrm{g})$ were used. The plates were incubated at $37^{\circ} \mathrm{C}$ for $16 \mathrm{~h}$ and the halo diameter corresponding to the phospholipase activity was measured.

\section{Antivenom Cross-Reactivity}

ELISA 96-well plate (Costar, Corning, New York, United States) was coated with $T$. serrulatus venom, $R$. crassicauda venom, or $R$. crassicauda chromatographic fractions $(2 \mu \mathrm{g} /$ well $)$ in $0.05 \mathrm{M}$ carbonate/bicarbonate buffer, pH 9.6 (100 $\mu \mathrm{L} /$ well), and incubated overnight at $4^{\circ} \mathrm{C}$. Control wells were coated with non-immune horse serum (diluted 1:50 in 0.05 M carbonate/bicarbonate buffer, $\mathrm{pH}$ 9.6, $100 \mu \mathrm{L} /$ well), scorpion antivenom, or arachnid antivenom, which also includes antibodies specific to $T$. serrulatus scorpion venom; Butantan Institute, SP, Brazil). The plates were washed 3 times with PBS pH 7.2, blocked by adding $250 \mu \mathrm{L}$ of PBS containing $2 \%(\mathrm{w} / \mathrm{V})$ non-fat dry milk (Molico, Nestlé, Bebey, Switzerland - MPBS), and incubated for $2 \mathrm{~h}$ at $37^{\circ} \mathrm{C}$. Plates were washed 3 times with PBS-0.05\% Tween (PBS-T) and 3 times with PBS. Then, scorpion or arachnid antivenoms (diluted $1: 1000$ in 1\% MPBS) were added, following $1 \mathrm{~h}$ incubation at $37^{\circ} \mathrm{C}$. The plates were washed as previously and $100 \mu \mathrm{L}$ of anti-horse polyclonal antibodies conjugated with peroxidase (IgG-HRP, A6917, Sigma-Aldrich, St. Louis, MO, United States, 1:3000 in 1\% MPBS) were added to the wells following $1 \mathrm{~h}$ incubation at room temperature. The plates were washed again with PBS-T and PBS. In each well, $100 \mu \mathrm{L}$ of OPD- $\mathrm{H}_{2} \mathrm{O}_{2}$ (SIGMAFAST ${ }^{\mathrm{TM}}$ OPD tablet, Sigma-Aldrich, St. Louis, MO, United States) were added and incubated for $15 \mathrm{~min}$ at room temperature for color development. The reaction was stopped with $50 \mu \mathrm{L}$ of $1 \mathrm{M} \mathrm{H}_{2} \mathrm{SO}_{4}$ (Merck, Kenilworth, NJ, United States) and absorbance was measured at $490 \mathrm{~nm}$. The assay was carried out in duplicate and the results were analyzed by GraphPad Prism 8.4 software (La Jolla, CA, United States), using one-way ANOVA, followed by Tukey's post hoc test.

\section{Cell Line and Culture}

Mice macrophages J774.1 cell line (ATCC, Rockville, MD, United States) were cultured in RPMI-1640 medium supplemented with $10 \%(\mathrm{~V} / \mathrm{V})$ fetal bovine serum (FBS), and $1 \%(\mathrm{w} / \mathrm{V})$ gentamicin, under standard conditions $\left(37^{\circ} \mathrm{C}\right.$, $5 \% \mathrm{CO}_{2}$, and $95 \%$ humidity). Approximately $2.5 \times 10^{4}$ cells diluted in $100 \mu \mathrm{L}$ of medium were plated per well and incubated 
overnight under the standard conditions. The medium was aspirated and replaced by medium without FBS (100 $\mu \mathrm{l}$ per well) containing $T$. serrulatus venom (TsV), Ts $1, R$. crassicauda venom $(\mathrm{RcV})$, or $\mathrm{Rcl}(100 \mu \mathrm{g} / \mathrm{mL})$, and incubated for $24 \mathrm{~h}$ at standard conditions.

\section{Cytotoxicity and Cytokine Levels}

The viability of J774.1 cells was determined using the 3-(4,5dimethylthiazol-2-yl)-2,5-diphenyltetrazolium bromide (MTT) colorimetric assay (80). After $24 \mathrm{~h}$ of incubation with different stimuli (see cell line culture Section), 5\% MTT in RPMI was added to the plated cells. Following $3 \mathrm{~h}$ of incubation with MTT, $50 \mu \mathrm{L}$ of $20 \%$ sodium dodecyl sulphate (SDS) in $0.01 \mathrm{M} \mathrm{HCl}$ were added and cells were kept at room temperature until complete precipitate solubilization. Absorbance was measured at $570 \mathrm{~nm}$ and viability was expressed as the percentage (\%) compared to unstimulated cells.

Concentrations of TNF- $\alpha$, IL- 6 , and IL- $1 \beta$ were evaluated from the cell supernatants by ELISA using specific antibodies (purified and biotinylated) and cytokine standards, according to the manufacturers' instructions (R\&D Systems, MSP, United States).

\section{Protein Expression by Western Blotting}

After removing the supernatants, J774.1 cells were lysed in radioimmunoprecipitation assay buffer RIPA buffer (Merk, Darmstadt, Germany) containing protease and phosphatase inhibitors. Protein quantification was performed using detergentcompatible methodology (DC Protein Assay, Bio-rad, CA, United States). Proteins were separated by polyacrylamide gel electrophoresis (Bolt Bis-Tris 4-12\% Plus Gel, Life Technologies, CA, United States) and transferred to $0.22 \mu \mathrm{m}$ nitrocellulose membrane (GE Healthcare, Madison, WI, United States). The membranes were blocked in Tris buffered saline (TBS) solution containing $0.01 \%$ Tween, and 5\% non-fat dry milk (Molico, Nestlé, Bebey, Switzerland). Recombinant anti-NF-кB p65 antibody [E379] (Abcam, United States) and Phospho-NFкB p65 (S536; Abcam, United States) were added at 1:5000 dilution in blocking solution; Anti-GAPDH clone (71.1; SigmaAldrich, St. Louis, MO, United States) was added at 1:20,000 dilution. HRP-conjugated antibodies (KPL, Gaithersburg, MD, United States) were used at the dilution of 1:5000. ECL (GE Healthcare, Chicago, IL, United States) was used for band detection. Quantification was performed using Software ImageJ 1.52a (NIH, MD, United States). Data are representative of arbitrary units relative to the control (GAPDH).

\section{Expression of Voltage-Gated Ion Channels in Xenopus laevis Oocytes}

For the expression of Nav channels (hNav1.1, rNav1.2, rNav1.4, hNav1.5, mNav1.6, the invertebrate channel BgNaV1.1 and the auxiliary subunits $\mathrm{r} \beta 1, \mathrm{~h} \beta 1$, and TipE) in $X$. laevis oocytes, the linearized plasmids were transcribed by using the T7 or SP6 mMessage-mMachine Transcription Kit (Thermo Fisher Scientific, United States). The harvesting of stage V-VI oocytes from anesthetized female $X$. laevis frogs was as previously described (81). Oocytes were injected with $50 \mathrm{~nL}$ of cRNA at a concentration of $1 \mathrm{ng} / \mathrm{nL}$ by using a microinjector (Drummond Scientific Company, Broomall, PA, United States). The oocytes were incubated in a solution containing (in $\mathrm{mM}$ ): $\mathrm{NaCl}, 96 ; \mathrm{KCl}$, 2; $\mathrm{CaCl} 2,1.8 ; \mathrm{MgCl} 2,2$; and HEPES, 5 ( $\mathrm{pH}$ 7.4). This solution was supplemented with $50 \mathrm{mg} / \mathrm{L}$ gentamicin sulfate. The use of $X$. laevis was approved by the Ethical Committee for animal experiments of the University of Leuven (P186/2019).

\section{Electrophysiological Assays}

Sodium currents were recorded using the two-microelectrode voltage-clamp technique (TEVC) at room temperature (20$\left.25^{\circ} \mathrm{C}\right)$. The recordings were processed by a GeneClamp 500 amplifier (Axon Instruments, United States) controlled by a pClamp data acquisition system (Axon Instruments, United States). Whole-cell currents from oocytes were recorded 1-5 days after injection. Currents and voltage electrodes had resistances from 0.8 to $1.4 \mathrm{M} \Omega$ and were filled with $3 \mathrm{M} \mathrm{KCl}$. Currents were sampled at $20 \mathrm{kHz}$ and filtered at $2 \mathrm{kHz}$ using a four-pole low-pass Bessel filter. Leak subtraction was performed using a $-\mathrm{P} / 4$ protocol. For the assays, Rcl diluted in ND96 solution was added directly to the recording chamber to obtain the desired final concentration $(1 \mu \mathrm{M})$. Experiments were performed at least three times.

For the activation protocols, $100 \mathrm{~ms}$ test depolarization, ranging from $-90 \mathrm{mV}$ to $+70 \mathrm{mV}$, were applied from a holding potential of $-90 \mathrm{mV}$, in $5 \mathrm{mV}$ increments at $5 \mathrm{~s}$ intervals. For the inactivation protocols, double pulses with a conditioning pulse applied from a holding potential of $-100 \mathrm{mV}$ to a range of potentials from $-90 \mathrm{mV}$ to $0 \mathrm{mV}$, in $5 \mathrm{mV}$ increments for $50 \mathrm{~ms}$, immediately followed by a test pulse to $0 \mathrm{mV}$ (or $-5 \mathrm{mV}$ ) were employed. Data were normalized to the maximal Nav current amplitude (Imax), plotted against the pre-pulse potential and fitted using the Boltzmann equation: $\mathrm{I}_{\mathrm{Na}} / \mathrm{I}_{\max }=\{(1-$ $\left.\mathrm{C}) /\left(1+\exp \left[\left(\mathrm{V}-\mathrm{V}_{\mathrm{h}}\right) / \mathrm{k}\right)\right]\right\}+\mathrm{C}$, where $\mathrm{I}_{\max }$ is the maximal $\mathrm{I}_{\mathrm{Na}}, \mathrm{V}_{\mathrm{h}}$ is the voltage corresponding to half-maximal inactivation, $\mathrm{V}$ is the test voltage, $\mathrm{k}$ is the slope factor, and $\mathrm{C}$ is a constant representing a non-inactivating persistent fraction (close to 0 in control).

\section{Nociceptive Assays}

Injections of $0.01 \mathrm{~mL}$ of $R$. crassicauda venom (1, 3, and $9 \mu \mathrm{g})$ and $\operatorname{Rcl}(0.5,2$, and $4 \mu \mathrm{g})$ into the plantar surface (ipl) of the right hind paw of C57BL/ 6 mice (male, $18-22 \mathrm{~g}, n=5$ ) were performed. Control groups received ipl injections of TsV $(1 \mu \mathrm{g})$, Ts1 $(0.5 \mu \mathrm{g})$, or physiological solution $(0.9 \% \mathrm{NaCl})$. The time mice spent either licking or lifting/shaking the injected paw was recorded at $5 \mathrm{~min}$ intervals for $35 \mathrm{~min}$. All experiments were conducted according to the guidelines of the Ethic Principles in Animal Experimentation of School of Medicine of Ribeirão Preto University of São Paulo, with the license number 246/2019.

\section{Statistical Analyzes}

The experiments were performed at least in triplicate and the results were expressed by standard deviations (SD). The statistical significance of the results was assessed using analysis of variance (one-way ANOVA or two-way ANOVA) followed by Tukey 
post hoc test through the GraphPad Prism 8.4.3 software. $P$ values $<0.05$ were considered significant.

\section{DATA AVAILABILITY STATEMENT}

The datasets presented in this study can be found in online repositories. The names of the repository/repositories and accession number(s) can be found in the article/ Supplementary Material.

\section{ETHICS STATEMENT}

The animal study was reviewed and approved by Comissão de Ética no Uso de Animais (CEUA-FMRP).

\section{AUTHOR CONTRIBUTIONS}

$\mathrm{MP}, \mathrm{KB}, \mathrm{JT}, \mathrm{TC}$, and EA designed the research. CA, KB, FC, IO, $\mathrm{CB}, \mathrm{GA}-\mathrm{S}, \mathrm{KZ}, \mathrm{MR}, \mathrm{EP}-\mathrm{J}$, and SP performed the research. MP, $\mathrm{KB}, \mathrm{IO}, \mathrm{GW}, \mathrm{SP}, \mathrm{LQ}, \mathrm{LF}$, and UZ analyzed the data. All authors contributed to writing of the manuscript.

\section{REFERENCES}

1. Nelsen DR, Nisani Z, Cooper AM, Fox GA, Gren ECK, Corbit AG, et al. Poisons, toxungens, and venoms: redefining and classifying toxic biological secretions and the organisms that employ them. Biol Rev Camb Philos Soc. (2014) 89:450-65. doi: 10.1111/brv.12062

2. Chippaux JP, Goyffon M. Venomous and poisonous animals - I. Overview. Med Trop. (2006) 66:215-20.

3. Souza WMP, Alexandre-Silva G, Cerni FA, Oliveira IS, Zottich U, Bassoli BK, et al. Envenomings caused by venomous animals in Roraima: a neglected health problem in the Brazil's Northernmost state. TCR. (2019) 3:1-8. doi: 10.24966/TCR-3735/100011

4. Cupo P. Bites and stings from venomous animals: a neglected Brazilian tropical disease. Rev Soc Bras Med Trop. (2015) 48:639-41. doi: 10.1590/00378682-0387-2015

5. Pucca MB, Cerni FA, Pinheiro Junior EL, Bordon KCF, Amorim FG, Cordeiro FA, et al. Tityus serrulatus venom - a lethal cocktail. Toxicon. (2015) 108:27284. doi: 10.1016/j.toxicon.2015.10.015

6. Pucca MB, Oliveira FN, Schwartz EF, Arantes EC, Lira-da-Silva RM. Scorpionism and dangerous species of Brazil. In: Gopalakrishnakone P editor. Toxinology: Scorpion Venoms. Dordrecht: Springer Netherlands. (2014). p. 124. doi: 10.1007/978-94-007-6647-1_20-1

7. Torrez PPQ, Dourado FS, Bertani R, Cupo P, França FOS. Scorpionism in Brazil: exponential growth of accidents and deaths from scorpion stings. Revista da Sociedade Brasileira de Medicina. Tropical. (2019) 52:e20180350. doi: 10.1590/0037-8682-0350-2018

8. di Caporiacco, L. Diagnosi preliminari di specie nuove di Aracnidi della Guiana britannica. Monitore zoologico Italiano. (1947) 56: 20-34.

9. Lenarducci ÂRIP, Pinto-da-Rocha R, Lucas SM. Descrição de uma nova espécie de Rhopalurus thorell, 1876 (scorpiones: Buthidae) do nordeste brasileiro. Biota Neotropica. (2005) 5:173-80. doi: 10.1590/S167606032005000200015

10. Lourenço WR, Pinto-da-Rocha R. A reappraisal of the geographic distribution of the genus Rhopalurus Thorell (Scorpiones, Buthidae) and description of two new species. Biogeographica. (1997) 73:181-91.

\section{FUNDING}

We thank Conselho Nacional de Desenvolvimento Científico e Tecnológico (CNPq, The National Council for Scientific and Technological Development, grant nos. 307155/2017-0 and 306479/2017-6); the Coordenação de Aperfeiçoamento de Pessoal de Nível Superior - Brasil (CAPES, Finance Code 001, scholarship no. 88881.186830/2018-01 to EP-J); and Fundação de Amparo à Pesquisa do Estado de São Paulo (FAPESP, São Paulo Research Foundation, grant nos. 2017/04724-4 and 2019/101736 and scholarships no. 2017/14035-1 to FC, nos. 2017/035809 and 2018/21233-7 to IO, no. 2016/04761-4 to EP-J, no. $2017 / 02314 / 3$ to $\mathrm{MR}$, and no. $2017 / 00586-6$ to GW). JT was funded by GOC2319N and GOA4919N (F.W.O. Vlaanderen) and CELSA/17/047 (BOF, KU Leuven). SP is a postdoctoral fellow supported by KU Leuven funding (PDM/19/164). MP acknowledges funding support from the Programa Institucional de Apoio á Pesquisa (Pró-Pesquisa-UFRR).

\section{SUPPLEMENTARY MATERIAL}

The Supplementary Material for this article can be found online at: https://www.frontiersin.org/articles/10.3389/fimmu. 2020.02011/full\#supplementary-material

11. Teruel R, Tietz AK. The true identity of Rhopalurus pintoi MelloLeitão, 1932, with notes on the status and distribution of rhopalurus crassicauda caporiacco, 1947 (Scorpiones: Buthidae). Euscorpius. (2008) 70: $1-4$.

12. Esposito LA, Yamaguti HY, Souza CA, Pinto-Da-Rocha R, Prendini L. Systematic revision of the neotropical club-tailed scorpions, Physoctonus, Rhopalurus, and Troglorhopalurus, revalidation of Heteroctenus, and descriptions of two new genera and three new species (Buthidae: Rhopalurusinae). Bull Am Museum Nat His. (2017) 415:1-136. doi: 10.1206/0003-0090-415.1.1

13. Ministério da Saúde do Brasil DATASUS - Doenças e Agravos de Notificação. (2020). Available online at: https://datasus.saude.gov.br/acesso-a-informacao/ doencas-e-agravos-de-notificacao-de-2007-em-diante-sinan/ (accessed July 6, 2020).

14. Chippaux J-P. Emerging options for the management of scorpion stings. Drug Des Devel Ther. (2012) 6:165-73. doi: 10.2147/DDDT.S24754

15. Cupo P, Cupo P. Clinical update on scorpion envenoming. Rev Soc Bras Med Trop. (2015) 48:642-9. doi: 10.1590/0037-8682-0237-2015

16. Ahmadi S, Knerr JM, Argemi L, Bordon KCF, Pucca MB, Cerni FA, et al. Scorpion venom: detriments and benefits. Biomedicines. (2020) 8:118. doi: 10.3390/biomedicines 8050118

17. Pucca MB, Zoccal KF, Roncolato EC, Bertolini TB, Campos LB, Cologna CT, et al. Serrumab: a human monoclonal antibody that counters the biochemical and immunological effects of Tityus serrulatus venom. J Immunotoxicol. (2012) 9:173-83. doi: 10.3109/1547691X.2011.649220

18. Laustsen AH, Gutiérrez JM, Knudsen C, Johansen KH, Bermúdez-Méndez E, Cerni FA, et al. Pros and cons of different therapeutic antibody formats for recombinant antivenom development. Toxicon. (2018) 146:151-75. doi: 10.1016/j.toxicon.2018.03.004

19. Utkin YN. Animal venom studies: current benefits and future developments. World J Biol Chem. (2015) 6:28-33. doi: 10.4331/wjbc.v6.i2.28

20. Pucca MB, Cerni FA, Janke R, Bermúdez-Méndez E, Ledsgaard L, Barbosa JE, et al. History of envenoming therapy and current perspectives. Front Immunol. (2019) 10:598. doi: 10.3389/fimmu.2019.01598

21. Williams HF, Layfield HJ, Vallance T, Patel K, Bicknell AB, Trim SA, et al. The urgent need to develop novel strategies for the diagnosis and 
treatment of snakebites. Toxins. (2019) 11:363. doi: 10.3390/toxins1106 0363

22. de Oliveira GH, Cerni FA, Cardoso IA, Arantes EC, Pucca MB. Tityus serrulatus envenoming in non-obese diabetic mice: a risk factor for severity. J Venom Anim Toxins Incl Trop Dis. (2016) 22:26. doi: 10.1186/s40409-0160081-8

23. Schwartz EF, Diego-Garcia E, Rodríguez de la Vega RC, Possani LD. Transcriptome analysis of the venom gland of the Mexican scorpion Hadrurus gertschi (Arachnida: Scorpiones). BMC Genomics. (2007) 8:119. doi: 10.1186/ 1471-2164-8-119

24. Verano-Braga T, Dutra AAA, León IR, Melo-Braga MN, Roepstorff P, Pimenta AMC, et al. Moving pieces in a venomic puzzle: unveiling post-translationally modified toxins from Tityus serrulatus. J Proteome Res. (2013) 12:3460-70. doi: $10.1021 /$ pr 4003068

25. Fox JW, Serrano SMT. Insights into and speculations about snake venom metalloproteinase (SVMP) synthesis, folding and disulfide bond formation and their contribution to venom complexity. FEBS J. (2008) 275:3016-30. doi: $10.1111 / j .1742-4658.2008 .06466 . x$

26. Cerni FA, Pucca MB, Amorim FG, de Castro Figueiredo Bordon K, Echterbille J, Quinton L, et al. Isolation and characterization of Ts19 Fragment II, a new long-chain potassium channel toxin from Tityus serrulatus venom. Peptides. (2016) 80:9-17. doi: 10.1016/j.peptides.2015.06.004

27. Cologna CT, Rodrigues RS, Santos J, de Pauw E, Arantes EC, Quinton L. Peptidomic investigation of Neoponera villosa venom by high-resolution mass spectrometry: seasonal and nesting habitat variations. J Venom Anim Toxins Incl Trop Dis. (2018) 24:6. doi: 10.1186/s40409-018-0141-3

28. Bordon KCF, Wiezel GA, Amorim FG, Arantes EC. Arthropod venom Hyaluronidases: biochemical properties and potential applications in medicine and biotechnology. J Venom Anim Toxins Incl Trop Dis. (2015) 21:43. doi: 10.1186/s40409-015-0042-7

29. Oliveira-Mendes BBR, de, Miranda SEM, Sales-Medina DF, Magalhães BF, Kalapothakis Y, Souza RP, et al. Inhibition of Tityus serrulatus venom hyaluronidase affects venom biodistribution. PLoS Negl Trop Dis. (2019) 13:e0007048. doi: 10.1371/journal.pntd.0007048

30. Ramanaiah M, Parthasarathy PR, Venkaiah B. Isolation and characterization of hyaluronidase from scorpion (Heterometrus fulvipes) venom. Biochem Int. (1990) 20:301-10.

31. Batista CVF, Román-González SA, Salas-Castillo SP, Zamudio FZ, GómezLagunas F, Possani LD. Proteomic analysis of the venom from the scorpion Tityus stigmurus: biochemical and physiological comparison with other Tityus species. Comp Biochem Physiol C Toxicol Pharmacol. (2007) 146:147-57. doi: 10.1016/j.cbpc.2006.12.004

32. Lourenço WR. The evolution and distribution of noxious species of scorpions (Arachnida: Scorpiones). J Venom Anim Toxins Includ Trop Dis. (2018) 24:1. doi: 10.1186/s40409-017-0138-3

33. Uzawa S. Über die phosphomonoesterase und die phosphodiesterase. $J$ Biochem. (1932) 15:1-10. doi: 10.1093/oxfordjournals.jbchem.a125167

34. Dhananjaya BL, D'souza CJM. An overview on nucleases (DNase, RNase, and phosphodiesterase) in snake venoms. Biochem Moscow. (2010) 75:1-6. doi: 10.1134/S0006297910010013

35. Fox JW. A brief review of the scientific history of several lesserknown snake venom proteins: 1-amino acid oxidases, hyaluronidases and phosphodiesterases. Toxicon. (2013) 62:75-82. doi: 10.1016/j.toxicon.2012.09. 009

36. Boldrini-França J, Cologna CT, Pucca MB, Bordon KCF, Amorim FG, Anjolette FAP, et al. Minor snake venom proteins: Structure, function and potential applications. Biochim Biophys Acta Gen Subj. (2017) 1861:824-38. doi: 10.1016/j.bbagen.2016.12.022

37. Díaz-García A, Ruiz-Fuentes JL, Yglesias-Rivera A, Rodríguez-Sánchez $\mathrm{H}$, Riquenes Garlobo Y, Fleitas Martinez O, et al. Enzymatic analysis of venom from cuban scorpion Rhopalurus junceus. J Venom Res. (2015) 6:11-8.

38. Rodríguez-Ravelo R, Coronas FIV, Zamudio FZ, González-Morales L, López GE, Urquiola AR, et al. The Cuban scorpion Rhopalurus junceus (Scorpiones, Buthidae): component variations in venom samples collected in different geographical areas. J Venom Anim Toxins Incl Trop Dis. (2013) 19:13. doi: 10.1186/1678-9199-19-13
39. Zamudio FZ, Conde R, Arévalo C, Becerril B, Martin BM, Valdivia HH, et al. The mechanism of inhibition of ryanodine receptor channels by imperatoxin I, a heterodimeric protein from the scorpion Pandinus imperator. J Biol Chem. (1997) 272:11886-94. doi: 10.1074/jbc.272.18.11886

40. Conde R, Zamudio FZ, Becerril B, Possani LD. Phospholipin, a novel heterodimeric phospholipase A2 from Pandinus imperator scorpion venom. FEBS Lett. (1999) 460:447-50. doi: 10.1016/S0014-5793(99)01392-7

41. Valdez-Cruz NA, Batista CVF, Possani LD. Phaiodactylipin, a glycosylated heterodimeric phospholipase A2 from the venom of the scorpion Anuroctonus phaiodactylus. Eur J Biochem. (2004) 271:1453-64. doi: 10.1111/j.1432-1033.2004.04047.x

42. Louati H, Krayem N, Fendri A, Aissa I, Sellami M, Bezzine S, et al. A thermoactive secreted phospholipase A2 purified from the venom glands of Scorpio maurus: relation between the kinetic properties and the hemolytic activity. Toxicon. (2013) 72:133-42. doi: 10.1016/j.toxicon.2013.06.017

43. Schwartz EF, Camargos TS, Zamudio FZ, Silva LP, Bloch C, Caixeta F, et al. Mass spectrometry analysis, amino acid sequence and biological activity of venom components from the Brazilian scorpion Opisthacanthus cayaporum. Toxicon. (2008) 51:1499-508. doi: 10.1016/j.toxicon.2008.03.029

44. Ramanaiah M, Parthasarathy PR, Venkaiah B. Purification and properties of phospholipase A2 from the venom of scorpion, (Heterometrus fulvipes). Biochem Int. (1990) 20:931-40.

45. Incamnoi P, Patramanon R, Thammasirirak S, Chaveerach A, Uawonggul $\mathrm{N}$, Sukprasert S, et al. Heteromtoxin ( $\mathrm{HmTx}$ ), a novel heterodimeric phospholipase A(2) from Heterometrus laoticus scorpion venom. Toxicon. (2013) 61:62-71. doi: 10.1016/j.toxicon.2012.10.012

46. Bordon KCF, Cologna CT, Arantes EC. Scorpion venom research around the world: Tityus serrulatus. In: Gopalakrishnakone P, Possani LD, Schwartz EF, Rodríguez de la Vega RC editors. Scorpion Venoms. Dordrecht: Springer Netherlands. (2014). p. 411-37. doi: 10.1007/978-94-007-6404-0_7

47. Polikarpov I, Junior MS, Marangoni S, Toyama MH, Teplyakov A. Crystal structure of neurotoxin Ts1 from Tityus serrulatus provides insights into the specificity and toxicity of scorpion toxins. J Mol Biol. (1999) 290:175-84. doi: 10.1006/jmbi.1999.2868

48. Pucca MB, Cerni FA, Peigneur S, Bordon KCF, Tytgat J, Arantes EC. Revealing the function and the structural model of Ts4: Insights into the "Non-Toxic" toxin from Tityus serrulatus venom. Toxins. (2015) 7:2534-50. doi: 10.3390/ toxins 7072534

49. Tanaka T, Narazaki M, Kishimoto T. IL-6 in inflammation, immunity, and disease. Cold Spring Harb Perspect Biol. (2014) 6:a016295. doi: 10.1101/ cshperspect.a016295

50. Abbas AK, Lichtman AH, Pillai S, Baker DL, Baker A. Cellular and Molecular Immunology. 9th ed. Philadelphia, PA: Elsevier. (2018).

51. Fukuhara YDM, Reis ML, Dellalibera-Joviliano R, Cunha FQC, Donadi EA. Increased plasma levels of IL-1 $\beta$, IL-6, IL-8, IL-10 and TNF- $\alpha$ in patients moderately or severely envenomed by Tityus serrulatus scorpion sting. Toxicon. (2003) 41:49-55. doi: 10.1016/S0041-0101(02)00208-8

52. Zoccal KF, Bitencourt CS, Sorgi CA, Bordon KCF, Sampaio SV, Arantes EC, et al. Ts6 and Ts2 from Tityus serrulatus venom induce inflammation by mechanisms dependent on lipid mediators and cytokine production. Toxicon. (2013) 61:1-10. doi: 10.1016/j.toxicon.2012.10.002

53. Reis MB, Zoccal KF, Gardinassi LG, Faccioli LH. Scorpion envenomation and inflammation: beyond neurotoxic effects. Toxicon. (2019) 167:174-9. doi: 10.1016/j.toxicon.2019.06.219

54. Zoccal KF, Bitencourt CS, Paula-Silva FWG, Sorgi CA, de Castro Figueiredo Bordon K, Arantes EC, et al. TLR2, TLR4 and CD14 recognize venomassociated molecular patterns from Tityus serrulatus to induce macrophagederived inflammatory mediators. PLoS One. (2014) 9:e88174. doi: 10.1371/ journal.pone. 0088174

55. Zoccal KF, Bitencourt CS, Secatto A, Sorgi CA, Bordon KCF, Sampaio SV, et al. Tityus serrulatus venom and toxins Ts1, Ts2 and Ts6 induce macrophage activation and production of immune mediators. Toxicon. (2011) 57:1101-8. doi: 10.1016/j.toxicon.2011.04.017

56. Zoccal KF, Sorgi CA, Hori JI, Paula-Silva FWG, Arantes EC, Serezani CH, et al. Opposing roles of LTB4 and PGE2 in regulating the inflammasomedependent scorpion venom-induced mortality. Nat Commun. (2016) 7:10760. doi: 10.1038/ncomms10760 
57. Pucca MB, Peigneur S, Cologna CT, Cerni FA, Zoccal KF, Bordon KCF, et al. Electrophysiological characterization of the first Tityus serrulatus alpha-like toxin, Ts5: Evidence of a pro-inflammatory toxin on macrophages. Biochimie. (2015) 115:8-16. doi: 10.1016/j.biochi.2015.04.010

58. Shih VF-S, Tsui R, Caldwell A, Hoffmann A. A single NFкB system for both canonical and non-canonical signaling. Cell Res. (2011) 21:86-102. doi: 10. $1038 / \mathrm{cr} .2010 .161$

59. Kendellen MF, Bradford JW, Lawrence CL, Clark KS, Baldwin AS. Canonical and non-canonical NF- $\mathrm{B}$ signaling promotes breast cancer tumor-initiating cells. Oncogene. (2014) 33:1297-305. doi: 10.1038/onc.2013.64

60. Díaz-García A, Ruiz-Fuentes JL, Frión-Herrera Y, Yglesias-Rivera A, Riquenez Garlobo Y, Rodríguez Sánchez H, et al. Rhopalurus junceus scorpion venom induces antitumor effect in vitro and in vivo against a murine mammary adenocarcinoma model. Iran J Basic Med Sci. (2019) 22:759-65. doi: 10.22038/ ijbms.2019.33308.7956

61. Mikaelian AG, Traboulay E, Zhang XM, Yeritsyan E, Pedersen PL, Ko $\mathrm{YH}$, et al. Pleiotropic anticancer properties of scorpion venom peptides: Rhopalurus princeps venom as an anticancer agent. DDDT. (2020) 14:881-93. doi: 10.2147/DDDT.S231008

62. Pucca MB, Cerni FA, Cordeiro FA, Peigneur S, Cunha TM, Tytgat J, et al. Ts8 scorpion toxin inhibits the Kv4.2 channel and produces nociception in vivo. Toxicon. (2016) 119:244-52. doi: 10.1016/j.toxicon.2016.06.014

63. Isbister GK, Volschenk ES, Balit CR, Harvey MS. Australian scorpion stings: a prospective study of definite stings. Toxicon. (2003) 41:877-83. doi: 10.1016/ S0041-0101(03)00065-5

64. Pucca MB, Cerni FA, Oliveira IS, Timothy Jenkins TP, Argemí LM, Sørensen $\mathrm{CV}$, et al. Bee updated: current knowledge on bee venom and bee envenoming therapy. Front Immunol. (2019) 10:2090. doi: 10.3389/fimmu.2019. 02090

65. Dib-Hajj SD, Binshtok AM, Cummins TR, Jarvis MF, Samad T, Zimmermann K. Voltage-gated sodium channels in pain states: Role in pathophysiology and targets for treatment. Brain Res Rev. (2009) 60:65-83. doi: 10.1016/j. brainresrev.2008.12.005

66. Cardoso FC, Lewis RJ. Sodium channels and pain: from toxins to therapies. $\mathrm{Br}$ J Pharmacol. (2018) 175:2138-57. doi: 10.1111/bph.13962

67. Pucca MB, Amorim FG, Cerni FA, Bordon KCF, Cardoso IA, Anjolette FAP, et al. Influence of post-starvation extraction time and prey-specific diet in Tityus serrulatus scorpion venom composition and hyaluronidase activity. Toxicon. (2014) 90:326-36. doi: 10.1016/j.toxicon.2014.08.064

68. Smith JJ, Herzig V, King GF, Alewood PF. The insecticidal potential of venom peptides. Cell Mol Life Sci. (2013) 70:3665-93. doi: 10.1007/s00018-0131315-3

69. García-Gómez BI, Coronas FIV, Restano-Cassulini R, Rodríguez RR, Possani LD. Biochemical and molecular characterization of the venom from the Cuban scorpion Rhopalurus junceus. Toxicon. (2011) 58:18-27. doi: 10.1016/j. toxicon.2011.04.011

70. Rodríguez-Ravelo R, Restano-Cassulini R, Zamudio FZ, Coronas FIV, Espinosa-López G, Possani LD. AK+ channel blocking peptide from the
Cuban scorpion Rhopalurus garridoi. Peptides. (2014) 53:42-7. doi: 10.1016/ j.peptides.2013.10.010

71. Cerni FA, Pucca MB, Peigneur S, Cremonez CM, Bordon KCF, Tytgat J, et al. Electrophysiological characterization of Ts6 and Ts7, K+ channel toxins isolated through an improved Tityus serrulatus venom purification procedure. Toxins. (2014) 6:892-913. doi: 10.3390/toxins6030892

72. Rochat H, Rochat C, Kupeyan C, Miranda F, Lissitzky S, Edman P. Scorpion neurotoxins: a family of homologous proteins. FEBS Lett. (1970) 10:349-51. doi: 10.1016/0014-5793(70)80470-7

73. Oliveira-Mendes BBR, Miranda ', Sales-Medina DF, Magalhães B, de F, Kalapothakis Y, et al. Hyaluronidase: the spreading factor of Tityus serrulatus venom. bioRxiv [Preprint]. (2018). doi: 10.1101/487298 bioRxiv:487298,

74. Schägger H, von Jagow G. Tricine-sodium dodecyl sulfate-polyacrylamide gel electrophoresis for the separation of proteins in the range from 1 to $100 \mathrm{kDa}$. Anal Biochem. (1987) 166:368-79. doi: 10.1016/0003-2697(87)90587-2

75. Edman P, Begg GA. Protein sequenator. Eur J Biochem. (1967) 1:80-91. doi: 10.1111/j.1432-1033.1967.tb00047.x

76. Cevallos MA, Navarro-Duque C, Varela-Julia M, Alagon AC. Molecular mass determination and assay of venom hyaluronidases by sodium dodecyl sulfatepolyacrylamide gel electrophoresis. Toxicon. (1992) 30:925-30. doi: 10.1016/ 0041-0101(92)90392-i

77. Bjork W. Purification of phosphodiesterase from Bothrops atrox venom, with special consideration of the elimination of monophosphatases. J Biol Chem. (1963) 238:2487-90.

78. Valério AA, Corradini AC, Panunto PC, Mello SM, Hyslop S. Purification and characterization of a phosphodiesterase from Bothrops alternatus snake venom. J Protein Chem. (2002) 21:495-503.

79. Habermann E, Hardt KL. A sensitive and specific plate test for the quantitation of phospholipases. Anal Biochem. (1972) 50:163-73.

80. Mosmann T. Rapid colorimetric assay for cellular growth and survival: application to proliferation and cytotoxicity assays. J Immunol Methods. (1983) 65:55-63. doi: 10.1016/0022-1759(83)90303-4

81. Peigneur S, Cheneval O, Maiti M, Leipold E, Heinemann SH, Lescrinier E, et al. Where cone snails and spiders meet: design of small cyclic sodium-channel inhibitors. FASEB J. (2019) 33:3693-703. doi: 10.1096/fj.201801909R

Conflict of Interest: The authors declare that the research was conducted in the absence of any commercial or financial relationships that could be construed as a potential conflict of interest.

Copyright (C) 2020 Abreu, Bordon, Cerni, Oliveira, Balenzuela, Alexandre-Silva, Zoccal, Reis, Wiezel, Peigneur, Pinheiro-Júnior, Tytgat, Cunha, Quinton, Faccioli, Arantes, Zottich and Pucca. This is an open-access article distributed under the terms of the Creative Commons Attribution License (CC BY). The use, distribution or reproduction in other forums is permitted, provided the original author(s) and the copyright owner(s) are credited and that the original publication in this journal is cited, in accordance with accepted academic practice. No use, distribution or reproduction is permitted which does not comply with these terms. 